\title{
The Role of Weather on Schooling and Work of Young Adults in Madagascar ${ }^{1}$
}

\author{
Francesca Marchetta \\ Université Clermont Auvergne, CNRS, IRD \\ David E. Sahn \\ Cornell University ${ }^{2}$ \\ Luca Tiberti \\ Partnership for Economic Policy (PEP) and Université Laval
}

\begin{abstract}
We examine the impact of rainfall variability and cyclones on schooling and work among a cohort of teens and young adults in Madagascar. We estimate a bivariate probit model using a panel survey conducted in 2004 and 2011 in this poor island nation, which is frequently affected by extreme weather events. Our results show that negative rainfall deviations and cyclones reduce the probability of attending school and encourage young men and, to a greater extent, women to enter the work force, and they reduce their French and math test scores. Less wealthy households are most likely to experience this school-to-work transition in the face of rainfall shocks. The finding is consistent with poorer households having less savings and more limited access to credit and insurance, which reduces their ability to cope with rainfall shortages. We also find that there are both contemporaneous and lagged effects of the weather shocks, and that they are of a similar magnitude. Our findings are robust to the use of a linear probability model, as well as a wide range of definitions of rainfall variations.
\end{abstract}

Keywords: Africa; agricultural labor; climate shocks; employment; schooling

JEL Codes: I25; J43; Q54

\footnotetext{
${ }^{1}$ The authors would like to thank Olivier Santoni for the excellent work in the preparation of rainfall and cyclones data, Simone Bertoli for useful suggestions, as well as the participants to seminar presentations at Laboratoire M Montpelliérain d'Economie Théorique et Appliquée (LAMETA), Montpellier; at NOVAFRICA, Lisbon; to the 3rd Institute of Labor Economics (IZA)/Department for International Development (DFID)-Growth and Labour Markets in Low Income Countries Programme (GLM-LIC) Research Conference in Washington; and to the Labor and Development Workshop, Paris. Francesca Marchetta acknowledges the support received from the Agence Nationale de la Recherche of the French government through the program "Investissements d'avenir" (ANR-10-LABX-14-01). David E. Sahn has verified that no financial support of research is appropriate. Luca Tiberti acknowledges the financial support from the Partnership for Economic Policy (PEP), with funding from the DFID of the United Kingdom (or UK Aid), and the Government of Canada through the International Development Research Center (IDRC). The usual disclaimers apply.

2 Corresponding Author: David E. Sahn, Cornell University, B16 Martha Van Rensselaer Hall, Ithaca, NY 14853. Phone: 607/255-8931. Fax:607/255-0178. Email: David.Sahn@cornell.edu
} 


\section{Introduction}

Weather events can affect human capital formation and exert a long-lasting influence on individual wellbeing and on macroeconomic performance. This is of particular concern in developing countries, where high rates of poverty, a labor force primarily employed in agriculture, and limited credit and insurance markets can magnify the effects of rainfall shortages. In this article, we study the influence of rainfall variability and cyclones on schooling and entry into the labor market of young adults in Madagascar.

Madagascar is one of the ten countries in the world with the highest Climate Risk Index (Kreft et al. 2016), being extremely vulnerable to cyclones, floods, and droughts. These extreme events threaten the country's fragile ecology and the agricultural sector, in which nearly three out of four workers are employed (World Development Indicators; the data refer to 2015). According to a recent report from the US Agency for International Development (USAID) (https:/www.usaid.gov/madagascar/environment), climate scientists expect flooding and erosion to increase in some regions of Madagascar, as rainfall increases in intensity; while in the south, rainfall is expected to become less predictable, leading to greater extremes, including more frequent drought.

This article provides new evidence on (1) how normal rainfall variability affects schooling and working decisions, and schooling performance; (2) the extent to which there is heterogeneity across households in these responses; and (3) the impact of acute weather shocks, particularly cyclones, on schooling and work choices.

We focus on a cohort of young men and women in Madagascar who were between 14 and 16 years old in 2004 and were surveyed again between November 2011 and January 2012. We build a balanced annual panel data set from 2004 to 2011, with information on the school and working situation of each individual, derived from retrospective questions included in the questionnaire of the 2011 round 
of the survey. We match individual-level data with satellite-based, fine-grained information on rainfall and with data on cyclones, using time-varying information on the place of residence of each individual.

Our empirical analysis, based on a non-separable agricultural household conceptual framework, involves estimating a bivariate probit model of schooling and work for the young adult cohort members (CMs) residing in rural areas of Madagascar. We also use time and geographic fixed-effects. The identification strategy relies on the large temporal and spatial historical variations in rainfall between 2004 and 2011, across 181 rural communities. Results show that a positive rainfall deviation from the long-term average increases the (average) probability of school enrollment by 2.5 percent, while reducing the probability of being engaged in work by up to 4.1 percent. We also observe lagged effects, indicating that there is some persistence of the impact of climate shocks in the year that follows the shock itself.

We also find that the observed effects are heterogeneous across households. Specifically, they are attenuated when individuals are from wealthier households. This suggests that assets help to mitigate the effect of transitory adverse weather conditions. Women are more likely than men to be pushed to the labor market following a negative weather event. Our results also show that rainfall deviations affect cognitive test scores among school attendees and that cyclones reduce the probability of being enrolled in school by 15 percent. While we cannot empirically test the mechanisms through which cyclones impact schooling and work decisions, a plausible conjecture is that these rainfall events destroy roads, interrupt electricity, and damage schools, contributing to school dropout. Our findings are robust also when a linear probability model is used. We also employ a falsification test, estimating the effects of rainfall deviations observed in the period of the year that is not part of the agricultural growing season, which serves to confirm that the impact mechanism is the variation in the agricultural production due to a change in rainfall. 
This article contributes to a rapidly growing body of research, which examines how extreme weather events influence economic outcomes (Dell, Jones, and Olken 2014), and more specifically, human capital. Prior research has shown that weather events have a significant impact on human capital through several dimensions: income (Levine and Yang 2014); wages (Mahajan 2017); nutrition and health (Maccini and Yang 2009; Tiwari, Jacoby, and Skoufias 2017); and consumption and calorie intake (Asfaw and Maggio 2017). More relevant to our specific interest in schooling and work, Villalobos (2016) found that daily meteorological variations (precipitation and temperature) had a deleterious impact on schooling outcomes in Costa Rica, and that students in more humid and warmer villages were at a higher risk of absenteeism and poor academic outcomes. Groppo and Kraehnert (2017) showed that students living in Mongolian districts affected by severe winters were less likely to complete compulsory school. The impacts were significant only for students living in herding households. The authors concluded that the effects were not associated with increased child labor in herding or with the closure of school facilities, but rather were related to the drop in household income due to the loss of livestock. Maccini and Yang (2009) found that favorable rainfall conditions, occurring in the year of birth, had a positive effect on educational outcomes for adult Indonesian women. Jensen (2000) estimated that adverse rainfall conditions in Côte d'Ivoire decreased school enrollment of children.

Regarding the effects on labor outcomes, Jacoby and Skoufias (1997) and Jessoe, Manning and Taylor (2018) found that weather shocks caused negative income fluctuations, which led to households withdrawing their children from school in order to increase labor market engagement, with possibly long-lasting negative effects on poverty and development. By assuming that households respond to exogenously determined wages, Shah and Steinberg (2017) found that positive rainfall conditions increased average wages in the Indian rural sector. This encouraged parents to increase their children's 
on-farm labor supply and, as a consequence, schooling participation decreased. Rainfall shocks, in this context, act as a "productivity and, thus, wage shifter" (Shah and Steinberg 2017, 538). The authors found that such an effect outweighs the income effect on schooling, given that it is a normal good. In other words, households could be motivated to lower human capital investments in their children's education when wages for low-paying, unskilled jobs increase. Shah and Steinberg (2017) also found that higher rainfall in early life (defined as the period spent in utero and up to the age of two years) had a positive impact on math and reading tests and reduced the probability of lagging behind in school or of never being enrolled. Dumas (2015) showed that child labor increased with higher rainfall in Tanzania in the absence of efficient labor markets. This effect is explained by what the author calls the "price effect": the increase in labor productivity pushed parents to make their children work on the family farm. Finally, Colmer (2017) finds that parental income uncertainty —as proxied by rainfall variability — determines a change in the allocation of children's time-from labor on the farm to school. ${ }^{3}$

Overall, the existing literature suggests that a positive weather event and, more specifically, a positive deviation in rainfall, can have ambiguous effects on schooling and labor, strongly dependent on the context. This ambiguity reflects the conflicting income and price effects associated with shocks. That is, we might observe an income effect whereby a positive shock increases agricultural production, so that parents are able to send children to school for longer periods, with their entry into the labor market postponed. Conversely, we could also observe a price effect: the increase in labor productivity associated with better climatic conditions could encourage parents to have their children work, thus increasing the probability of school dropout. However, the overall effect might be even more complex

\footnotetext{
${ }^{3}$ The literature also explores the impact of weather events on the diversification choice. For example, Skoufias, Bandyopadhyay, and Olivieri (2017) showed that ex ante rainfall variability in India was associated with more diversification of rural households from agricultural to off-farm sectors. Similarly, Bandyopadhyay and Skoufias (2015) found that ex ante rainfall variability risks in Bangladesh pushed adult members, who were not the heads of their households away from the agricultural sectors, also at a cost of a lower total household welfare.

${ }^{2}$ Other papers have adopted measures of rainfall based on deviation from the historical trend (for example, Björkman-Nyqvist 2013; Dumas 2015; Shah and Steinberg 2017; Sesmero, Ricker-Gilbert, and Cook 2018).
} 
when households' consumption and production choices are interconnected and depend on endogenously determined shadow prices. The complexity is particularly important in contexts like Madagascar, where labor markets are heterogeneous and affected by large transactions costs. Within a non-separable agricultural household framework, we find that the indirect effect (through the change in the shadow price) is negative. Henceforth, the overall effect is positive only if the direct (income) effects dominate. In several important ways, our study adds to the growing literature on the effects of weather events on human capital. First is our unique focus on a cohort of young adults. We focus on this group because they face unique challenges and risks; teenagers and young adults are particularly vulnerable to shocks, to the extent that they drop out of school when pushed into the labor market as a household coping mechanism. Second, this article also examines the effects of rainfall variability on school test scores, not just enrollments. Third, we look at the impact of both normal rainfall deviations and acute weather shocks on schooling and work choices. Fourth, we provide new evidence on the heterogeneity of households' resilience to climatic shocks, owing to the detailed retrospective information we have obtained, which allows us to include household wealth when the cohort members were children in the model. Additionally, the length of our panel data enables us to control for eventual migration episodes, as well as to check for the robustness of our models when individual fixed effects are included.

The remainder of the article is structured as follows: the next section introduces the conceptual framework that underpins our estimation approach. The subsequent section provides a description of the context of our study, introduces the data employed in the econometric analysis, and presents relevant descriptive statistics. The estimation strategy that we employ is discussed in the following section, and the next to last section describes the results of the econometric analysis. Finally, the last section draws the main conclusions and discusses the policy implications of our work. 


\section{Conceptual Framework}

Weather shocks can have immediate and lagged effects on school and work decisions. In this study we define negative weather shocks (or, rainfall shortages), which can contribute to drought conditions, as rainfall events that are below the historical local trend. Conversely, a positive weather shock occurs when the rainfall deviation from the historical local trend is above zero. ${ }^{4}$ In considering these positive and negative deviations, the underlying assumption is that less rain will adversely affect productivity and yields; conversely, above normal rains are favorable (for example, Dillon, McGee, and Oseni 2015), with the exception occurring when these positive deviations are large and associated with floods. In Madagascar, such acute rainfall events occur primarily as cyclones, which are differentiated from normal weather deviations in our models.

In our model we rely on the data that we collected that contains information on the exact month the CM left school and/or entered the labor market. The data also allow us to distinguish between immediate (or contemporaneous) and lagged effects of rainfall deviations on schooling and working decisions. As for the contemporaneous effect, CMs may or may not complete their school year, depending on the current year's rainfall—a decision affected by the households' expected revenues in the current agricultural season. In our models, these immediate effects may result in CMs leaving school and/or entering the labor market before the beginning of the harvest season in June.

Concerning the lagged effects, households may decide to keep their children at school (for example, to pursue a new schooling year in September) or to send them to work (for example, by around November, at the start of the next agricultural season), depending on the production of and revenues generated from the crops grown in the previous rainy season. The decision as to whether a child remains

\footnotetext{
${ }^{4}$ Other papers have adopted measures of rainfall based on deviation from the historical trend (for example, BjörkmanNyqvist 2013; Dumas 2015; Shah and Steinberg 2017; Sesmero, Ricker-Gilbert, and Cook 2018).
} 
in school during the agricultural cycle, which follows the agricultural season in which the shocks occurred, represents the lagged effects that are captured by the rainfall variable observed in year $t-1$ on school or work status in year $t$.

Figure 1 shows the definition of our school, work, and rainfall variables, with respect to the months of the year. For the purpose of our analysis, we considered an individual to be in school in year $t$, if she was attending or completed school in the schooling year that began in September of year $t-1$ (that is, she did not drop out of school before June of year $t$ ). We considered an individual at work in year $t$, if she reported having been employed, including unpaid work in a family enterprise, on or before May in year $t$. Thus, we did not consider her to have worked in year $t$, if she started working after June in year $t$ (for these individuals, we assigned a working status for the year $t+1$ ); but she was considered as working if she had worked between month 6 and month 12 of year $t-1 .{ }^{5}$ Our rainfall variable in year $t$ is defined over the period November $(t-1)$ through April ( $t$ ), which broadly corresponds to the rainy season throughout the country. Consistently, the historical means are estimated for the same period of the year (between November of year $t-1$ and April of year $t$ ). Since our research focuses on rural areas, we defined our outcomes in accordance with the agricultural season of rice, which is the main crop in Madagascar. More than two-thirds of our sampled individuals reported rice as the main cultivated crop. While maize is an important secondary crop, its agricultural calendar closely resembles that of rice (See http://www.fao.org/agriculture/seed/cropcalendar/welcome.do).

\footnotetext{
${ }^{5}$ We also run the model using a different (but qualitatively similar) definition of work, that is, considering the individual at work in year $t$ if she entered the labor market in year $t$ or before. Results do not substantially differ from the results of the model estimated using our preferred definition of work. Moreover, our data allow us to distinguish across the following types of work: wage worker, own account/employer, and family worker. Wage workers represent only $7 \%$ of the cohort members in the labor market, and the distinction between own account worker and family worker is not informative enough in a context that is dominated by smallholder family farms. We also have data on whether the individual works in the primary, secondary, or tertiary sector. Nevertheless, the large majority $(85 \%)$ are employed in the farm sector. These characteristics of our data and the context in rural Madagascar, therefore, preclude us from adopting other meaningful definitions of work.
} 


\section{$<$ INSERT FIGURE 1 approximately HERE $>$}

A large majority of rural households are primarily engaged in agricultural activities, either working their own land or as hired laborers on someone else's land. ${ }^{6}$ Also, as found in Tanzania (Tiberti and Tiberti 2015) and several other countries in sub-Saharan Africa, because of heterogeneity among workers and high transaction costs across households, the labor market in rural Madagascar is imperfect or absent (see the examples reported in de Janvry and Sadoulet 2006). In such a context, engagement in the selling or purchasing of a good in an imperfect market might be unprofitable for households and, for this reason, production and consumption decisions are interconnected. Hence, we believe that the nonseparable agricultural household model (AHM) (see, for example, Singh, Squire, and Strauss 1986) is an appropriate framework for our empirical strategy. ${ }^{7}$ More precisely, consistent with the non-separable model, we assume that consumption, production, and labor market decisions are interrelated, and consequently, exogenous shocks such as rainfall deviations affect the endogenously determined shadow wages of labor and family members' time allocation. As a consequence, the effect of the rainfall shock on a CM's decision is not simply given by the direct income (or production) effect (with the endogenous price held constant), but also by an indirect effect through the shock's impact on the endogenous prices. Typically, for this type of approach, comparative statics analysis is a useful tool to understand the expected sign of the impact of an exogenous shock on a farm household's behavior.

Starting with a standard setting (see, for example, Henning and Henningsen 2007), we assume that farm households maximize their utility function, $U$, which depends on the vector, $\boldsymbol{C}$, of consumption

\footnotetext{
${ }^{6}$ Data used in the empirical analysis show that only $27 \%$ of sample households did not cultivate any land between 2004 and 2011 , while only $10 \%$ of them did not engage in agricultural activities over the period. We consider a household engaged in agricultural activities if it cultivates land or if the CM or her father is engaged in the agricultural sector. See the Results Section for the definition of "non-agricultural household."

${ }^{7}$ Jessoe, Manning, and Taylor (2018) proposed a similar framework to study the effects of weather changes on employment and migration patterns in Mexico.
} 
of purchased and own-produced commodities, and of leisure, and on some household characteristics $s^{c}$. Utility maximization, $\max U\left(\boldsymbol{C}, s^{c}\right)$, is subject to the production technology constraint $G(\boldsymbol{X}, R, z)=0$, the time constraint $T-\left|X_{l}\right|+X_{l}^{h}-X_{l}^{s}-C_{l} \geq 0$, and the budget constraint $P_{c} \boldsymbol{C} \leq P_{x} \boldsymbol{X}-g\left(X_{l}^{h}, s^{l}\right)+$ $f\left(X_{l}^{S}, s^{l}\right)$. A usual multi-input-multi-output production function is $G($.$) , dependent on a vector of$ agricultural inputs $R$, both variable and fixed, such as land; outputs $\boldsymbol{X}$ (positive); and exogenous factors $z$, such a rainfall deviations. $T$ is the total time available to a farm household; $\left|X_{l}\right|$ is the total time that labor is engaged on a household's farm, which is the sum of family labor ${ }^{8}$ and hired labor, $X_{l}^{h}$; off-farm supplied labor is $X_{l}^{s}$; and $C_{l}$ is the time in leisure (a category in which we include child schooling). ${ }^{9} P_{c}$ and $P_{x}$ are the price of commodities and inputs/outputs, respectively, whereas $g($.$) and f($.$) denote the$ cost function of hired labor and the income function of off-farm work, respectively, both affected by labor market characteristics, $s^{l}$. As found in Henning and Henningsen (2007), under non-separability, the marginal cost of hiring labor and the marginal revenue from off-farm work correspond to the shadow wage.

Let us consider a change in an exogenous input $z$, such as rainfall. By assuming that farm households demand on-farm labor and supply off-farm labor simultaneously, the determinants of our endogenous variables of interest, whether the $\mathrm{CM}$ is in school or working $Q$, is as follows (de Janvry, Fafchamps, and Sadoulet 1991):

\footnotetext{
${ }^{8}$ We assume that child and adult labor are substitutes for each other, and they are both factored in $\boldsymbol{X}_{\boldsymbol{l}}$. Also, once adult labor is used entirely - in farm or off-farm sectors - child labor is used as needed by the household, and, more importantly in our framework, the variation in the child shadow wage due to weather shocks is independent on the size of the adult labor. ${ }^{9}$ In accordance with Rosenzweig and Evenson (1977), child schooling and leisure can be considered as similar goods with respect, for example, to their respective shadow price. For this reason, for simplicity, we assume that child schooling is included in $C_{l}$. For example, the shadow prices of child schooling and leisure are both "positively correlated with the number of children and the opportunity cost of school attendance and child leisure" (Rosenzweig and Evenson 1977, 1067).
} 
(1) $\quad \frac{d Q}{d z}=\underbrace{\left.\frac{\partial Q}{\partial z}\right|_{P_{l}^{*}}}_{\begin{array}{c}\text { direct } \\ \text { component }\end{array}}+\underbrace{\frac{\partial Q}{\partial P_{l}^{*}} \frac{d P_{l}^{*}}{d z}}_{\begin{array}{c}\text { indirect } \\ \text { component }\end{array}}$

And, by applying the implicit function theorem to the time constraint,

$T-\left|X_{l}\right|+X_{l}^{h}-X_{l}^{S}-C_{l} \geq 0$, the shadow price $P_{l}^{*}$ adjustment is:

(2) $\frac{d P_{l}^{*}}{d z}=\frac{\frac{\partial X_{l}}{\partial z}+\frac{\partial C_{l}}{\partial y} \frac{\partial y}{\partial z}}{-\frac{\partial X_{l}+\frac{\partial X_{l}^{h}}{\partial P_{l}^{*}} \partial \frac{\partial X_{l}^{s}}{\partial P_{l}^{*}}-\frac{\partial C_{l}^{H}}{\partial P_{l}^{*}}}{\partial P_{l}^{*}}}$,

where $\partial C_{l} / \partial y \times \partial y / \partial z$ is the rainfall-induced income effect on the demand for leisure.

The sign of the numerator is expected to be positive. In fact, $\partial X_{l} / \partial z$, the effect of the total onfarm labor supply (family and hired labor), with respect to a change in rainfall, is expected to be positive because positive rainfall deviations (excluding floods) increase agricultural production and thus the demand for on-farm labor. A supporting result for this assumption is reported in Sadoulet and de Janvry $(1995,74)$ and in Jessoe, Manning, and Taylor (2018). The second term of the numerator is the product between the change in income resulting from positive rainfall deviations $(\partial y / \partial z)$ (see, for example, Bengtsson 2010), and the consequent income effect of the demand for leisure $\left(\partial C_{l} / \partial y\right)$. The effect of rainfall deviations on income, $\partial y / \partial z$, is expected to be positive and relatively high, especially in Madagascar where rainfed agricultural production is prevalent. Since leisure is normally assumed to be a non-inferior good, the second term is also positive.

The sign of the denominator is expected to be positive as well. The first term, $\partial X_{l} / \partial P_{l}^{*}$ (the own-price effect of on-farm labor), is expected to be negative. As shown in Henning and Henningsen (2007), with labor market imperfections caused by non-proportional variable transaction costs and labor heterogeneity, the cost of hiring on-farm workers is convex and the income function from off-farm 
economic activities is concave. If such hypotheses hold (as is plausible in our context), it follows that $\left(\partial X_{l}^{h} / \partial P_{l}^{*}-\partial X_{l}^{s} / \partial P_{l}^{*}\right)$ ranges between zero (autarky case) and infinity (if the labor market works perfectly). Finally, the own-price effect to Hicksian demand for leisure $\left(\partial C_{l}^{H} / \partial P_{l}^{*}\right)$ is negative. It follows that the better the functioning of the agricultural labor market (and so, the greater the integration to the labor market), the lower the indirect effect (tending toward zero).

If we return to our utility function $U\left(C, s^{c}\right)$, the direct (income) effect, given that schooling is a normal good, is expected to increase the likelihood of staying in school and reduce the likelihood of entering the labor market, especially since there will be less need to pull children out of school to help cope with the decline in agricultural output and earnings. In contrast, the likelihood of schooling decreases with positive changes in the shadow wage (as its opportunity cost increases); thus, the indirect effect of positive rainfall deviations is expected to be negative. Hence, the overall effect is positive if the direct effect dominates, and negative in the case when the indirect effect prevails. ${ }^{10}$ In the case of larger market imperfections, the indirect (negative) effect tends to increase in absolute terms (second component in Equation [2]). And larger market imperfections will conversely reduce the size of the direct (positive) effect.

Relatedly, negative rainfall deviations might affect test scores through two possible pathways: (1) by increasing poverty and vulnerability that, in turn, would generate stress, which is deleterious to cognitive abilities (see Mani et al. 2013); and (2) by increasing absenteeism, for school attendees only, that would negatively impact on test scores. Henceforth, we can expect that rainfall shocks could affect both the quantity and the quality of schooling.

\footnotetext{
${ }^{10}$ The change in the shadow prices of child education and working can also be affected by rainfall-induced changes in the price of commodities, complementary (to labor) inputs and substitutes. Other effects may come from the impact on the teachers' market and on non-farm labor markets, and weather-induced labor migration for hired workers. The latter effect is expected to be marginal in our study context, because a very low percentage of Malagasy farm households use hired labor in their agricultural production function.
} 
In addition to the direct and indirect effects discussed earlier, the CM's decision might be affected by infrastructure effects—-such as cyclones destroying schools, roads, and electric grids, as well as damaging other physical structures - that could prevent school attendance.

In the empirical analysis, we are not able to disentangle the relative importance of the direct and indirect effects on schooling and work decisions as identified above, but only the overall effect. In addition, our analysis tests for the existence of contemporaneous and lagged effects. For example, in the case of a negative weather shock from a lower rainfall leading to drought, we examine whether this effect is felt immediately, as evidenced by CMs dropping out of school during the agricultural season in which the rainfall shock occurs, or instead, choosing not to enroll in school and to work in the academic year subsequent to the shock. In the case of positive deviations in rainfall, we also examine contemporaneous and lagged effects. Better rains lead to higher family income, which may increase both the likelihood that CMs remain in school during the current agricultural calendar, as well as encourage parents to enroll CMs in school the following academic year, rather than having them enter the labor market. In the case of cyclones, we only look at contemporaneous impacts of the destruction of infrastructure. ${ }^{11}$

Finally, we test for the existence of heterogeneity to vulnerability. Pre-shock assets can help households to mitigate the effects of the shocks, as they can be used as buffer stocks and as collateral for credit loans, especially in the case of transitory shocks. Such capacities can differ, however, by the size of a household's asset holdings. Therefore, we expect that weather shocks impact CMs differently, depending on their households' abilities to buffer shocks, which in this article, is proxied by a household

\footnotetext{
${ }^{11}$ In the case of inefficient government infrastructure, cyclones could have an extended lagged effect as well, because the physical infrastructure may not be rebuilt for some time. We have tried to include the lagged cyclone effect in our model, but it turns out not to be significant. Also, extreme weather shocks such as cyclones, drought, or floods might affect demand for schooling directly through malnutrition or the disease environment. Both effects are not included in our theoretical framework, but can certainly be important ones.
} 
wealth index in the initial period. An intertemporal framework capturing the evolving abilities of households to cope with income shocks would be more appropriate. However, our wealth data are not observed on a yearly basis.

\section{Context, Data, and Descriptive Statistics}

Madagascar's geography, located between the Indian Ocean and the Mozambique Channel, often means the island is the terminus of tropical cyclones and storms that originate on the western coast of Australia. Most of the regions of the country are classified as high risk for cyclones, with the Eastern Coast being the most affected. The frequency of tropical cyclones is expected to decline in the next decades, but the cyclones' intensities will increase (Mavume et al. 2009; Hervieu 2015). The country is even more vulnerable to tropical cyclones due to its lack of good disaster warning strategies (Fitchett and Grab 2014). Between 2000 and 2011, a number of tropical cyclones have hit Madagascar, with the 2004 cyclones, Elita and Gafilo, being the most devastating of the storms, killing hundreds of people, leaving 200,000 people homeless, and destroying about 1,400 schools throughout the country (Rajaon, Randimbiarison, and Raherimandimby 2015). More recently, Enawo - the most destructive cyclone in more than a decade — struck in 2017, affecting nearly a half million people.

Although rainfall is expected to intensify in some regions of Madagascar, especially those vulnerable to cyclones, lower rainfall is projected in the south of the country (see https://www.usaid.gov/madagascar/environment). The past three years have been characterized by a prolonged drought, which was exacerbated by an exceptionally strong El Niño in 2015-16. According to the Food and Agriculture Organization of the United Nations (FAO), El Niño has resulted in the lowest precipitation in 35 years (FAO 2016). Drought has, in turn, contributed to crop failures, disease, and 
malnutrition. According to the United Nations Children's Fund (UNICEF), at the beginning of the academic year 2015-16, parents started to take children out of school, when teachers' and students' absenteeism increased as a result of drought conditions (UNICEF 2016).

In addition to strong winds, tropical storms are often accompanied by heavy rains and increasingly, widespread flooding. This is due in part to climate change and in part to environmental degradation. It is not only Madagascar's extreme vulnerability to weather events, but also the fact that its agricultural sector represents around one-quarter of the country's GDP, employing about 75 percent of the population engaged in small-scale landholding — which makes the country an interesting case to study, in terms of the impact of weather events on schooling and work decisions.

\section{Individual Data and Descriptive Statistics}

In this article, we use individual-level data from two surveys: the Madagascar Life Course Transition of Young Adults Survey (2011-2012) and the Progression through School and Academic Performance in Madagascar Survey (EPSPAM, 2004). These are the two latest rounds of a survey that follows a cohort of young adults born in the late 1980s. Both the 2004 and 2011-12 surveys collected comprehensive information on cohort members and their family members. The questionnaire included detailed modules on education, labor, migration, agriculture, family enterprises, health and fertility, and cognitive abilities, as well as household assets and housing conditions. The cohort-based sample also collected considerable retrospective data using recall techniques; for example, we know the exact month and year that a cohort member left school and the precise timing of entry into the labor force. The cohort-based sample was complemented by community surveys of social and economic infrastructure, as well as general information on the key historical developments in the villages where the CMs were living in 2004. We have information on 1,075 cohort members living in rural areas (roughly half of them are 
women) who were aged 21 to 23 at the time of the 2011-12 survey, and their average age in 2004 was 14.85 (Table A.1 in the supplementary appendix online provides more information on the descriptive statistics). ${ }^{12}$ Among them, $311 \mathrm{CMs}$ living in rural areas in 2004 left their community of origin between 2004 and 2011 to move to another Malagasy area; we defined them as (internal) migrants. Over the eight-year time span, we were unable to locate slightly less than 10 percent of the sample. ${ }^{13}$ This attrition rate is small over such a long duration, especially as compared to other individual-based panel data surveys collected in sub-Saharan Africa. ${ }^{14,15}$

Forty-eight communities surveyed in 2004 and 2011 were randomly selected from the 100 communities that participated in a school grade-based, nationwide testing program in 1998, the Programme d'Analyse des Systèmes Educatifs de la CONFEMEN (PASEC). Although these communities were from all regions of the country, in order for a school to be selected it had to have 20 students in a classroom. That is, each school in the country had an equal probability of being included, conditional upon it having 20 -student classrooms that could be used in the testing program.

Since we were interested in a random sample of all children in the cohort who were of second grade school age in 1998, we made two adjustments in the sample to ensure that it was representative of the entire population. The first was designed to deal with the fact that very small schools, with too few

\footnotetext{
${ }^{12}$ We have indeed 1,119 cohort members living in rural areas, but we are finally able to retain only 1,075 observations per year, because of missing values for some of the variables that we use in the regression analysis (that is, assets in 2004, age at school entry, and employment status of the parents).

13 The original sample included 1,236 rural cohort members; since we were able to find 1,119 of them, the overall attrition rate was around 9.5 percent.

${ }^{14}$ Other panels with similar duration, such as the Guatemalan studies (Grajeda et al. 2005; Behrman et al. 2014) and those reviewed by Alderman et al. (2001) and Baird, Hamory, and Miguel (2008) generally have far worse attrition problems. Likewise, the level of attrition that we observe compares favorably with those in the more recent Young Lives program, which focused on minimizing attrition rates (see http://www.younglives.org.uk/content/sampling-and-attrition). For example, in the Ethiopian case, attrition for the older cohort was 18\% between 2002 and 2016.

${ }^{15}$ Missing cohort members are broadly similar to those who have been interviewed. We explored whether there were significant mean differences in a range of characteristics, including gender, oral math score, written math score, written French score, father's education, mother's education, wealth, whether from an urban or rural household, and a remoteness index, which incorporates a long list of the community's physical infrastructure characteristics. The only significant difference observed was in the case of grade achievement, where we find that interviewed cohort members had completed 0.4 more years of schooling than missed cohort (attrited) members at baseline.
} 
students per grade were excluded from the 1998 sample; and the second was to address the fact that some children never enrolled in school. In the 2004 survey we supplemented the 48 PASEC communities with an additional 25 communities, randomly selected from primarily remote rural communities with small primary schools. In these new communities, we did a complete enumeration of all the children in the cohorts' age range and randomly selected 15 children of the same age as those of the original PASEC sample, regardless of whether they had ever enrolled in school. In addition, in each of the original 48 PASEC communities, we did a complete enumeration and selected 15 children who were not in the original PASEC sample. These steps were taken to make sure that we did not exclude those who had never attended school, or enrolled very late, which is not an uncommon occurrence in Madagascar. Thus, both 2004 and 2011-12 samples include cohort members who would not have been selected by the original 1998 PASEC school-based survey, because they never attended or were from very small schools.

At the end, we have 1,075 individuals in the 2004-12 panel from 55 rural sample communities. Twenty-three of these are communities were first surveyed in 2004, and 32 are from the original PASEC communities. Among the cohort members in our analysis, 393 are from the new communities and 726 are from the original PASEC communities. ${ }^{16}$

This sampling approach was designed to make the cohort nationally representative. Comparisons of descriptive statistics of the cohort with other nationally representative surveys indicate that we were able to achieve this objective (Aubery and Sahn 2017; Almanza and Sahn 2018). ${ }^{17}$

$<$ INSERT FIGURE 2 approximately here $>$

\footnotetext{
${ }^{16}$ Among those from the original PASEC communities, only 211 cohort members were first tested in schools in 1998.

17 The reality is that no survey in Madagascar conducted in the past decade can really be considered nationally representative, since the most recent census, upon which sampling frames have been built, was conducted in 1993 .
} 
Figure 2 shows the school-to-work transitions, by age of our cohort members, during the 2004 12 period. As expected, older members were less likely to attend school, while the share of those CMs engaged in economic activities increased rapidly with age. Also, individuals both attending school and working decreased over time, and the circumstance of being neither at school nor at work occurred most frequently when cohort members were 18 or 19 years old. In our sample of CMs in rural areas, no one who dropped out of school returned at a later date. This implies that a negative shock that induces people to leave school has permanent effects, including the lowering of human capital accumulation.

Table A.1 in the supplementary appendix online reports some descriptive statistics of all the control variables used in our econometric estimation and of various test scores used in separate regressions, in addition to rain-related variables. The tests for math, written French, and their combination, are standardized with mean zero and standard deviation of one. Item response theory is used to score the tests, as described by Das and Zajonc (2010). This method is preferred over equal weighting of each question because it weights questions according to a combination of their degree of discrimination and difficulty. The intuition behind this approach is that more weight is given to more difficult questions than easy questions that most of the population answers correctly.

These tests were administered at home, not at school, so their collection does not depend on school attendance. As reported in table A.1, about 46 percent of CMs left their households of origin between 2004 and 2011-12 and are now living in newly formed households. Twenty-nine percent of the CMs migrated out of their community during this time period. Almost half of them migrated within the same district of origin, 36 percent moved to another district of the same province, and only 17 percent 
moved to another province. Table A.1 also reports the percentage of households cultivating land in 2004 and the household asset index in the same year. ${ }^{18}$

In our models, we also rely on data from the community questionnaire, especially for a question on the topography of the village where individuals live. More specifically, we create a classification with the following categories: hills (where 47 percent of CMs live), coastal plains (10.5 percent), interior plains (12.5 percent), plateau (16 percent), valleys (12.5 percent), and others. The community questionnaire also provides information on the presence of the middle and high schools, as well as information about their year of construction, which we use in our models.

In terms of our focus on the impact of climate and weather data on schooling and work, we use the Köppen-Geiger climate classification system to identify the climatic zones of the country. This system first classifies geographical areas into five main climate groups: tropical, dry, temperate, continental, and polar. Then, it classifies each group by the seasonal precipitation type and the level of heat. According to the classification system, Madagascar is divided into eight climatic zones, as shown in figure A.1 in the supplementary appendix online. Table A.2, also in the supplementary appendix online, shows the distribution of the CMs, corresponding to the climatic zones in which they lived in 2004 and in 2011.

\section{Weather Data and Indicators}

Data on cyclones are taken from the Tropical Cyclones Windspeed Buffers 1970-2015, provided by the Global Risk Data Platform. ${ }^{19}$ We have information on the number and strength of cyclones that have hit

\footnotetext{
${ }^{18}$ We computed this measure of wealth (based on non-land assets), using principal component analysis on data observed in 2004, following the procedure used by Filmer and Pritchett (2001). More specifically, we used variables related either to the ownership of durable goods (i.e., radio, refrigerator, TV, bicycle, motorbike, car) or to the dwelling characteristics (i.e., availability of electricity, type of toilet, type of water provision, quality of walls, type of cooking practice, number of rooms per person).

${ }^{19}$ Data available at: http://preview.grid.unep.ch/index.php?preview=data\&events=cyclones\&evcat=1\&lang=eng
} 
sample communities. The strength of a cyclone is measured through the Saffir-Simpson hurricane wind scale (SSHWS). This scale classifies cyclones into five categories on the basis of the wind speed, from 1 (minimal strength, from 119 to $153 \mathrm{~km} / \mathrm{h}$ ) to 5 (maximal strength, more than $252 \mathrm{~km} / \mathrm{h}$ ). We also have information on tropical storms, which are approximately 63 to $118 \mathrm{~km} / \mathrm{h}$ in wind speed.

Figure A.2 in the supplementary appendix online shows how the communities where our cohort members live were affected by cyclones over the period 2004-2011. Table A.3, also in the supplementary index online, indicates that in 2004, when Cyclones Elita and Gafilo hit Madagascar, 64 percent of CMs had been directly impacted by a tropical storm, while almost 15 percent were hit by a tropical cyclone. The percentages were much lower for the following years, especially with respect to tropical cyclones.

Rainfall data is derived from the African Rainfall Climatology, version 2, of the National Oceanic and Atmospheric Administration (NOAA). They are gridded daily precipitation estimates from 1983 to 2011, centered over Africa at 0.1 degree (about $10 \times 10 \mathrm{~km}$ ) spatial resolution. ${ }^{20}$ In the article, we use the term Satellite-Based Units (SBUs) to designate these grid cells. SBUs do not correspond exactly to our sample communities, in terms of surface, but there is no more than one community in a grid cell.

In this study, we employ several rainfall-based indicators. First, we estimate the standardized rainfall deviations over the period November-April (rainy season), ${ }^{21}$ by taking the variation between the total amount of rain precipitation over these months in year $t$ and in SBU $s$ and the 1991-2011 average,

\footnotetext{
${ }^{20}$ We also tried to use station-based data from the CRU (Climatic Research Unit), but we decided not to use them due to their poor quality for our case study. Indeed, CRU 3.24 data - gridded data that interpolate between the ground stations with a resolution of $0.5 \times 0.5$ degrees - present a large number of observations with a zero anomaly between 2006 and 2009 . This is due to the lack of weather stations available within the radiuses that are used for rainfall and temperature observations. We also wanted to use the Standardized Precipitation Evapotranspiration Index (SPEI) to consider the effect of evapotranspiration, but, unfortunately, the SPEI database is based on CRU data for rainfall.

${ }^{21}$ Although there are some differences with respect to the beginning and end of the rainy season within the country, in most of the areas this season goes from November to April, with a few others experiencing a slightly shorter rainy season. See http://www.fao.org/agriculture/seed/cropcalendar/welcome.do (accessed October, 2018).
} 
normalized by its 1991-2011 standard deviation. This indicator captures (positive or negative) rainfall deviations with respect to the local, long-term average. Also, given that the measure is standardized to the SBU's average, differences in the yearly deviations across rainy and dry zones are comparable.

Figure A.3 in the supplementary index online shows the trend of the standardized rainfall deviation between 2004 and 2011, both at a national level and by climatic zone. Between 2004 and 2011, the standardized rainfall deviation ranged between -1.96 and 2.89 , relative to the long-term average. There are differences across climatic zones, which are useful for our analysis, as the positive (or negative) rainfall deviations vary across SBUs. The left panel of figure 3 shows the distribution of the rainfall deviation variable over the period 2004 to 2011 for all rural baseline SBUs (that is, we do not consider here migrants' destination SBUs). The right panel shows the distribution of the mean of the same variable calculated by SBU over the whole period. When we compare the two panels, we observe the distribution of the SBU mean to be more concentrated around zero. This confirms that, on average, rainfall deviation from the mean is zero over the period in our sample SBUs. In other words, the SBUs in our sample are not systematically characterized by a positive or by a negative rainfall deviation. This indicates that what we observe, within our period of interest, is the normal rainfall variability, and we are not analyzing years characterized by exceptional rainfall events. Moreover, this assures us that our measure of rainfall deviation does not capture SBU effects.

$<$ INSERT FIGURE 3 approximately HERE $>$ 
Based on the standardized rainfall indicator, we identified exclusive categories to capture, in particular, extreme rainfall shocks. ${ }^{22}$ We also defined a variable drought, that takes the value 1 when rainfall deviation is below the 20th percentile, as in Shah and Steinberg (2017).

Finally, we used a relative seasonality index to capture the degree of variability of rainfall through November to April for each year. In fact, it is not only the quantity of rain that falls in a year that matters, but also its distribution, or timing, during the year. If it all occurs in a few months of the year, the same quantity of rain can have different (sometimes, detrimental) effects on agricultural production and the integrity of infrastructure than if it falls more evenly throughout the year. Following Walsh and Lawler $(1981,202)$, we defined the seasonality index as "the sum of the absolute deviations of mean monthly rainfalls from the overall monthly mean, divided by the mean [...] rainfall" over November-April. This index ranges between 0 (if rainfall is distributed equally across months) and 1.20 or higher (if all the yearly rain falls in one or two months). According to the literature (see, for example, FAO 2016), for values between 0.4 and 1 , the index indicates areas with seasonal rainfall. According to our data, most of the climatic zones in Madagascar experienced one or more years in which rainfall was extremely unequally distributed.

\section{Estimation Strategy}

We assume that schooling and work decisions are interdependent. A cohort member can choose to be only at school, only at work, sharing her time between school and work, or neither at school nor at work. To allow interdependency of the different alternatives, as in Duryea and Arends-Kuenning (2003), we

\footnotetext{
${ }^{22}$ These are defined as follows: Category 1 if rainfall deviation is lower than -1 ; Category 2 if rainfall deviation ranges between -1 and 0 ; Category 3 if rainfall deviation ranges between 0 and 1; Category 4 if rainfall deviation ranges between 1 and 2; Category 5 if rainfall deviation is higher than 2.
} 
adopted a bivariate probit model, where we define $S^{*}$ and $W^{*}$ as the latent variables of attending school $(S)$ and participating in work activities $(W)$, respectively. Although we acknowledge that the bivariate probit model is best identified when at least one equation includes at least one independent variable that affects its corresponding outcome but not the outcome of the other equation, our estimation relies on the property of the bivariate model that allows us to take into account the correlation between the two alternatives, since school and work decisions are undoubtedly correlated decisions. ${ }^{23}$ Hence, our basic specification is:

$$
\left(S_{i t}^{*}=\boldsymbol{\beta}_{1}^{S} \boldsymbol{X}_{i t}+\beta_{2}^{S} \text { rain }_{s t}+\beta_{3}^{S} \text { rain }_{s t} * \operatorname{asset}_{i 2004}+\theta_{i t}^{S}+\mu_{z}^{S}+\theta_{t}^{S}+\boldsymbol{\varepsilon}_{i t}^{S}\right.
$$

(4)

$$
W_{i t}^{*}=\boldsymbol{\beta}_{1}^{W} \boldsymbol{X}_{i t}+\beta_{2}^{W} \text { rain }_{s t}+\beta_{3}^{S} \text { rain }_{s t} * \operatorname{asset}_{i 2004}+\theta_{i t}^{W}+\mu_{z}^{W}+\theta_{t}^{W}+\boldsymbol{\varepsilon}_{i t}^{W},
$$

where:

$$
S_{i t}=\left\{\begin{array}{ll}
1 & \text { if } S_{i t}^{*}>0 \\
0 & \text { if } S_{i t}^{*} \leq 0
\end{array}\right\}
$$

(6) $\quad W_{i t}=\left\{\begin{array}{ll}1 & \text { if } W_{i t}^{*}>0 \\ 0 & \text { if } W_{i t}^{*} \leq 0\end{array}\right\}$

In this model, $S_{i t}$ takes the value of 1 if the cohort member $i$ was enrolled in school during year $t$, and $W_{i t}$ equals 1 if the cohort member was engaged in economic activities. The definitions of the school and work variables have been detailed in Section 2 (also refer to figure 1). $\boldsymbol{X}_{i t}$ is a set of explanatory

\footnotetext{
${ }^{23}$ We also ran separate probit estimations (see table A.7 in the supplementary appendix online), and we found that the coefficient of the rainfall variable varies neither in magnitude nor in significance.
} 
variables that includes characteristics of the cohort member, of her parents, and of the community in which she resided in 2004, as illustrated in Section 3. In particular, consistent with the theoretical framework discussed previously, we control for the transaction costs (the presence of a paved road in the village and the quality of land are proxies for these costs), and we introduce factors influencing the shadow price of schooling (such as the father's and mother's education levels and health and working statuses, as well as the number of brothers and sisters) and labor (such as land endowment in 2004 and the value of assets other than land). The variable rain $_{s t}$ is one of the rainfall variables described in the previous section, as observed in SBU $s$, where the CM lived in the year $t$. By introducing the interaction of the rainfall variable with a household wealth index in 2004 , which is the initial year of the analysis, we allow for heterogeneous effects across households. ${ }^{24}$ More specifically, we can control for households' resilience to climatic shocks, which is hypothesized to vary according to the CM's initial wealth. We control for the CM's age (denoted by dummies $\theta_{i t}$ ), climatic zones z $\left(\mu_{z}\right)$, and the year $\left(\theta_{t}\right)$. The inclusion of these fixed effects ensures that our results are not biased by systematic differences related to these variables. ${ }^{25}$ Finally, $\boldsymbol{\varepsilon}_{i t}^{S}$ and $\boldsymbol{\varepsilon}_{i t}^{W}$ are normally distributed error terms, with $\operatorname{cov}\left(\varepsilon_{i t}^{S}, \varepsilon_{i t}^{W}\right)=\rho$. Standard errors are clustered at the SBU level. With our data, an unbiased identification of $\beta_{2}$ and $\beta_{3}$ is possible because of the large temporal and spatial variation in the SBUlevel rainfall deviations, which should not be correlated with any unobserved variables affecting school and work decisions $\left(\boldsymbol{\varepsilon}_{i t}^{S}\right.$ and $\left.\boldsymbol{\varepsilon}_{i t}^{W}\right)$.

\footnotetext{
${ }^{24}$ While we also have wealth of information for 2011 , we choose to use the lagged wealth to avoid possible reverse causality and limit the impact of unobservable heterogeneity on current school and work decisions.

${ }^{25}$ As to why we did not use fixed individual effects, most of the variables used in our estimations are binary; controlling for fixed individual effects requires enough variability within each observation, which is not the case with our data. Also, see the threads discussed by Greene (2004). It shall be noted that Fernández-Val and Weidner (2016) recently developed a new (unbiased) estimator for non-linear individual fixed effects models, but this method is not suitable for bivariate probit estimations. In addition, we believe that rainfall deviations are exogenous to individual schooling or working decisions; hence, adding individual fixed effects would not affect the rainfall-related coefficients.
} 
In a separate specification, we include a dummy that is equal to 1 if a cyclone (of at least strength 1) hit the community where the CM lived during year $t$. This is done in order to test whether experiencing a cyclone has an impact on the probability of attending school and/or being engaged in work. We also estimate a specification in which we introduce the rainfall variable at time $t-1$. This allows us to test for the existence of a lagged effect of rainfall deviation on schooling and working decisions.

One concern is that economic and social development or, more generally, differences in a given SBU can be systematically correlated with rainfall levels. If this is the case, rainfall might be associated with some unobserved determinants of school and work decisions. We employ two strategies to overcome such a possibility. First, we used rainfall levels normalized to local historical levels, so that high- or low-rainfall SBUs in year $t$ are defined only with respect to their historical trends and not with respect to other SBUs (which might be comparatively rainier). Second, we run a separate estimation in which we control for SBUs' fixed effects to test the robustness of our results and to make sure that rainfall deviations are not systematically associated with local development or other differences across SBUs, which may be indirectly related to school and work status (see specification 8 in table 3).

In this regard, the reader may wonder why we use this specification just for robustness purposes, and not as the main specification. Satellite-based units (SBUs) do not correspond to any administrative units in Madagascar. Additionally, the number of CMs in each SBU varies substantially by SBU and over time. For example, in the starting year (2004) about 12\% of the SBUs have 15 or less individuals, and in the final year (2011), this rate increases to $48 \%$. Such an increase is explained by the fact that roughly a third of the CMS in rural areas have migrated during the period of analysis. Specifically, about a third of these CMs migrated to an SBU with only 5 individuals or less. For these reasons, we believe that introducing the SBU fixed effects would capture, in some cases, the individual fixed effects, and 
would imperfectly capture any eventual systematic difference across SBUs. Related to this, non-linear models are generally not well suited to fixed-effects estimations as the number of fixed effects grows (the so-called incidental parameters problem, see Greene 2004).

Also, as debated in the literature (for example, Angrist and Pischke 2008), there is no consensus on the superiority of assuming a nonlinear relationship when the dependent variable is binary. Hence, for robustness purposes, we also estimate a linear probability model with SBU fixed effects (as done, for example, by Shah and Steinberg 2017). Our findings, reported in table A.7 in the supplementary index online, show a broad consistency between the estimators, so in the discussion of the results in this article, we focus on the bivariate probit, our preferred estimation model.

In addition, we acknowledge the concern that individual, unobserved heterogeneity may be correlated with our main explanatory variable, rainfall. This would be the case if past rainfall patterns were both correlated with current rainfall patterns and with unobserved individual characteristics. For instance, past unfavorable rainfall patterns could have reduced households' assets or increased their resilience to shocks. If so, what we would observe is not only the effect of current rainfall deviation but also the possible effect of the long-term pattern of rainfall. We are confident that this is not the case, because we do not use absolute values, but rather a standardized deviation from the long-term mean as the main explanatory variable for rainfall. Furthermore, we control for the wealth of the CM's household in 2004. Moreover, when we regress rainfall deviation on its lagged value, the lagged value is not significant. To further address this concern, as shown in table A.6, in the supplementary appendix online, we have checked as to whether rainfall deviation was correlated with a past rainfall pattern, over the period $1992-2012$, for which rainfall data are available. Through a simple regression analysis, we verified that our variable is not explained by the long-term mean of a range of other variables that measure precipitation, including the mean of the same variable, not normalized, and the mean of the 
variable measuring total precipitation from station data (normalized and not normalized) during the agricultural season or during the entire year.

In addition to estimating the impact of the quantity of schooling (proxied by attendance, as done in the bivariate analysis), we also estimate the effect of rainfall deviations on the learning quality, as measured by crystallized cognitive test scores (TS) for 2011. Similar to the specification presented above, our basic linear model is as follows:

$$
T S_{i}=\boldsymbol{\beta}_{1}^{T S} \boldsymbol{X}_{i}+\beta_{2}^{T S} \operatorname{rain}_{l}+\beta_{3}^{T S} \operatorname{rain}_{l} * \operatorname{asset}_{i 2004}+\theta_{i}^{T S}+\mu_{z}^{T S}+\boldsymbol{\varepsilon}_{i}^{T S}
$$

\section{Results}

The first set of results for key parameters is reported in table $1 .{ }^{26,27}$ The results for the full specification are also presented in table A.4 in the supplementary index online, which includes $\operatorname{arctanh}(\rho)$, a monotonic transformation, namely the Fisher's $Z$ transformation, of the correlation coefficient $\rho$ between $\boldsymbol{\varepsilon}_{i t}^{S}$ and $\boldsymbol{\varepsilon}_{i t}^{W}$, which has the same sign as $\rho . \operatorname{Arctanh}(\rho)$ is significantly different from zero and is negative. This means that the schooling and work choices are jointly determined and that unobserved factors, which increase the probability of attending school, also decrease the probability of working. Table 1 shows the effect of the continuous standardized rainfall deviation on school and work decisions. Rainfall deviations positively affect the probability of attending school while reducing the probability of being

\footnotetext{
${ }^{26}$ We have 1,075 observations for an 8-year time span, explaining the 8,600 total observations we report in the text.

${ }^{27}$ All variables included in table A.1 (included in supplementary appendix online), except the ones in italic, are used as control variables. We do not interpret their estimated coefficients as impact effect, but simply as a correlate effect. We recognize that some of the time-varying controls we include are possibly endogenous and could capture part of the rainfall effect. In particular, the working status of the mother (father) is likely to be influenced by rainfall deviation, as well as the dummy variable indicating if CM lives in a different household from the one she lived in 2004. We thus run our baseline models (specifications 2 and 4 ) without these potentially endogenous variables. Results, not included here, show that the coefficients of our main variables of interest - rainfall deviation, assets and their interaction - are not affected by the exclusion of these variables.
} 
engaged in a work activity (column 1). This finding is consistent with the expected positive effect of good rains on incomes. Unfortunately, our data do not allow us to test the direct impact of positive rainfall deviations on agricultural production, as has been done in various earlier studies (for example, Jayachandran [2006] and Shah and Steinberg [2017] for India; Bengtsson [2010] for Tanzania; Amare et al. [2018] for Nigeria). Nevertheless, in order to test whether our estimated effect operates through agricultural production, we have included in the regressions of rainfall deviations measured outside the agricultural season, which should exert no effect on schooling and work decisions. We thus run a falsification test, in which we include the rainfall variable defined over the non-rainy season, that is, from May to October. The coefficients for rainfall during the non-rainy season are always insignificant. ${ }^{28}$ This result corroborates our assumption that the impact mechanism is the variation in the agricultural production. Furthermore, we cannot disentangle the income from any price effect, which may be affecting (that is, reducing) the magnitude of the overall effect.

We also note that the effects are heterogeneous across households, which can be seen when we include the interaction of household wealth, measured at the time the CMs were 14 to 16 years of age, with rainfall (column 2). This interaction is negative and significant for schooling and positive for work, suggesting that the effect of rainfall deviation on the decision to attend school or work is attenuated when CMs are from wealthier households. This finding is consistent with our expectations and points to wealth and related factors, such as greater access to savings, credit and insurance, helping to buffer the impact of adverse weather events. This result is also consistent with the findings of Beegle, Dehejia, and

\footnotetext{
${ }^{28} \mathrm{We}$ also look at the effect on the numbers of livestock owned by the household in order to indirectly analyze the effect of rainfall deviation on agricultural production. The rationale is the following: livestock is often used as a proxy for farmers' wealth and consumption (see, for example, Amare et al. 2018), and we can reasonably assume that a reduction in agricultural production and incomes induces a drop in livestock holding, which is used as a buffer stock. We thus run a model in which the numbers of livestock owned in 2011 is regressed on the rainfall deviation for the 2011 agricultural season, together with the same set of regressors used in the biprobit model. We converted livestock numbers to a common unit through the conversion scale proposed in FAO (2011) for sub-Saharan Africa. Results show that rainfall shortages in the agricultural season are significantly associated with a reduction in the numbers of livestock.
} 
Gatti (2006), who found that asset holdings mitigated the (increasing) effects of transitory income shocks on child labor.

Specification 3 further adds the occurrence of cyclones into the model. Like rainfall shortages, cyclones reduce the probability of attending school and appear to push the cohort members into the workplace. We can safely assume that, in the case of cyclones, the CMs enter the workplace and drop out of school as a result of economic hardship, possibly exacerbated by damage to schools and related infrastructure that impede access to educational opportunities.

Specification 4 in table 1 adds the lagged rainfall and the interaction of the lagged rainfall with 2004 assets. The rainfall and interaction terms are not statistically significant at conventional levels in the schooling model. What is interesting is that the addition of the lagged rainfall variable and the interaction with the asset index do not affect the significance or magnitude of the contemporaneous effect. This corroborates the observation that the impacts of current and lagged rainfall events on schooling operate independently of one another. The probability of working is strongly affected by both current and lagged rainfall episodes. The sign, significance, and magnitude of the contemporaneous and lagged effects are very similar, and this also applies to the interaction between lagged rainfall and assets. $^{29}$

$<$ INSERT TABLE 1 approximately $>$

To gain insight into the magnitude of the impacts of cyclones and lagged and current rainfall shocks, table 2 presents the marginal effects, based on the specification in the last column in table 1 . The occurrence of a cyclone decreases the probability of being enrolled in school by 15.2 percentage points

\footnotetext{
${ }^{29}$ We also estimated a specification, including a quadratic term for the rainfall variable, in order to capture the effect of excessive rain and floods. This term is not significant.
} 
and increases the probability of being engaged in a work activity by 10.5 percentage points at mean asset levels. In terms of rainfall, looking at the last column of table 2, we find that a standard deviation ${ }^{30}$ increase in the standardized rainfall increases the probability of being enrolled in school by 2.5 percentage points (or about a 5 percent increase from the baseline probability of $49 \%$ ) and decreases the probability of being engaged in work by 4.1 percentage points (or roughly a 8 percent decrease from the baseline probability of 52\%), calculated at the samples' mean asset levels. Similarly, we find that lagged rainfall decreases the probability of work by 5.0 percentage points, slightly higher than contemporaneous rainfall, although the positive impact on school enrollment is only 1.4 percentage points (which is not, in any case, statistically significant).

\section{$<$ INSERT TABLE 2 approximately HERE $>$}

We also calculate the marginal effects at different levels of assets to determine the extent to which wealth buffers the impact of rainfall fluctuations. Table 2 shows the point estimates for the 25 th, 50th, and 75th percentiles of the asset distributions, and figure 4 plots the curves from the 10th to the 90th percentiles. At the 25 th percentile, the impact of a change in one unit of the rainfall measure is a 3.6 percentage point increase in the probability of school, as contrasted with only a 1.8 percentage point increase for CMs from households at the 75th percentile (for the latter, the effect is not statistically significant). Similarly, the change in the probability of working associated with a one-unit decline in rainfall is to raise the probability of work by 5.5 percentage points for those belonging to the 25 th percentile, while for CMs from households at the 75th percentile the increase in work probability is almost half that at 3.1 percentage points. As we get further toward the lower bounds of the asset

\footnotetext{
${ }^{30}$ Table A.5 in the supplementary appendix online provides information on how one unit of z-score (or, one standard deviation) translates into absolute $\mathrm{mm}$ of rainfall, by climatic zone and nationally.
} 
distribution, we can see that the impact of rainfall shocks on work and school choices is much greater than that for households with greater wealth and, conversely, the probabilities of going to school or working is less affected by climate shocks among CMs from wealthier families (figure 4).

\section{$<$ INSERT FIGURE 4 approximately HERE $>$}

We next consider several extensions and robustness checks, reported in table 3. First, we include an interaction with gender (column 5). The negative and significant interaction in the work equation suggests that young women in our cohort are even more susceptible to being pushed into the labor market with negative rainfall deviations than are male CMs. When the rains are particularly favorable, however, young women experience a stronger reduction in the probability of being engaged in a work activity.

In another specification (column 6), we exclude from the sample those individuals who migrated from the community where they lived in $2004 .{ }^{31}$ The reason for this exclusion is that the community variables that we introduced in the model - the presence of schools and the type of land - are from the community where the individual lived in 2004 . With such a specification, we also test whether our results are biased because of the endogeneity of migration decisions, which are also possibly related to rainfalls. According to our results, this does not seem to be the case, as our estimates are fairly robust, when migrants are excluded from the sample.

We also ran a model that excluded from the sample those CMs coming from households who were not engaged in the agricultural sector, which we define as households where none of the members

\footnotetext{
${ }^{31}$ In specification (6) we excluded individuals who moved out of their community of origin, starting from the year of their outmigration. For example, if an individual migrated in 2007, she is in the sample until 2006, but she is excluded from 2007 to 2011 . We also estimated the baseline model on the sample of 803 individuals who never changed their residences between 2004 and 2011. Results are stable.
} 
cultivated any land between 2004 and 2011 and where neither the CMs nor their fathers have reported that their primary sector of work is in agriculture. This allows us to check whether the rainfall effect is higher for "agricultural households". Results, reported in column 7 of table 3, are stable to the exclusion of non-agricultural households. We can infer from this model that the impact of weather shocks operates, at least in part, indirectly on schooling and work choices, for example, affecting food prices and availability, and more generally, labor market and economic conditions in the rural communities in which the CMs reside. Finally, in specification (8), we estimate the model using SBU fixed effects. Of course, for those CMs who migrated during our period, SBUs are not constant over time. Both rainfall coefficients are still significant and of a similar magnitude.

In table 4 we run a series of other robustness checks, by employing different definitions of the rainfall variable. We first show, in specification (9), the results of a model using rainfall measures based on the full year, not just the rainy season, to define the standardized rainfall deviation. As can be seen, this change does not qualitatively change the results. Specification (10) then reports the results based on a categorical definition of the rainfall deviation: impacts are stronger as rainfall deviation increases, both for schooling and work. In specification (11), we introduce a dummy variable, instead of the rainfall deviation, to analyze more directly the specific effect of drought. ${ }^{32}$ Results show that drought would generate a reduction in the probability of school attendance and an increase in the probability of being engaged in work activities, especially for the poorest CMs. Also, specification (12) introduces a seasonality index to assess whether a less even distribution of rainfall over the agricultural season affects the CMs' school and work decisions. While schooling is not affected by the intra-seasonal distribution of rainfall, a higher concentration of rainfall increases the probability of working, even though, again,

\footnotetext{
${ }^{32}$ As specified in the text, the variable, drought, takes the value 1 when rainfall deviation is below the 20 th percentile, as in Shah and Steinberg (2017). We also tried to adopt alternative definitions for drought, with thresholds ranging between 20th and 5 th percentiles, respectively. Results are robust, irrespective of the definition we use.
} 
assets holdings help households mitigate such a negative effect. A higher concentration of rainfall throughout the year is expected to negatively affect agricultural land productivity and consequently, the revenue of agricultural households. For this reason, our results suggest that young adults may enter the workforce to contribute to household income, even without having a large effect on schooling participation. Finally, as discussed in Hsiang (2016) and Hirvonen (2016), weather-related variables, such as rainfall and temperatures, can be correlated. In our work, by not introducing temperatures in our specifications, we could encounter a classical omitted variables issue, and the rainfall coefficients can be biased. In specification (13), we control for this concern by adding a temperature variable (based on the CRU data set and defined as a deviation from their local, long-term mean). We find that the rainfall coefficients are unaffected.

$<$ INSERT TABLE 3 approximately HERE $>$

$<$ INSERT TABLE 4 approximately HERE $>$

The concluding set of models look at the effect of contemporaneous and lagged rainfall deviations on various standardized cognitive test scores observed in 2011. In the first column of table 5 (labeled "full"), we present the model of the combined math and French test score for the complete sample. We show that the combined test score is affected only by immediate rainfall variations (in 2011), but not by rainfall in 2010. We find that a one standard deviation decrease in rainfall would immediately lower the test score by 0.326 standard deviations. In the next two columns, we run the model on subsets of cohort members - those who are still in school and those who are not. For those who are not attending school (no-school column), there is no impact on the test score, while in contrast, 
attendees show a significant impact, slightly stronger than in the case of the combined sample (school column). This would suggest that the "stress" channel was not a contributing factor, but instead only the "absenteeism" pathway explains the lower test score. Indeed, absenteeism and possibly related decline in the quality of schooling, could induce a contemporaneous decline in test scores and mirroring what occurs in terms of enrollment. Finally, the results are robust to using math and French language test scores separately. In the case of the former, we find that this is also affected by the lagged rainfall. We can conclude that negative rainfall variations reduce the accumulation of human capital through a combination of the quantity, and possibly, the quality of schooling, although we cannot disentangle their relative importance.

$<$ INSERT TABLE 5 approximately HERE $>$

\section{Conclusions}

In this article, we have explored the impact of weather events on school and work decisions of a cohort of young adults in Madagascar. This is a particularly important issue, given the evidence that human activity is contributing to rapid climate change, which may lead to more severe cyclones, more frequent droughts, more flooding, and a higher concentration of rainfall in certain periods within a given year. Further exacerbating the potential deleterious impacts of climate variability in poor countries, such as Madagascar, is the lack of well-established credit and insurance markets, as well as poverty that limits the ability of households to buffer the impact of rainfall shortages.

Our focus on the impact of weather events on schooling and work is especially pertinent to the cohort of teens and young adults we study, who are transitioning from school to work. Our work clearly 
shows the deleterious impact of rainfall shocks, causing young people to drop out of school and enter the labor market earlier to presumably mitigate the impact of drought, floods, and cyclones on livelihoods of rural households.

A priori, the sign of the impact of rainfall deviations on school and work is undetermined. According to the non-separable agricultural household conceptual framework we use, while a positive increase in rainfall deviation is expected to increase school attendance through an income (direct) effect, the sign of the indirect (through the rainfall-induced change in the shadow wage) effect is likely to be negative and its magnitude depends on the degree of imperfection of markets. Higher market imperfections, in turn, are expected to reduce the positive income effect, although we cannot test this directly.

Most affected by these weather events are the less wealthy households, as one would expect, given their more limited savings, less access to credit and insurance, and generally more limited ability to cope with negative shocks. We also find that there are both contemporaneous and lagged effects of the weather shocks, and that they are of a similar magnitude. The impact mechanism is the change in the agricultural production due to a variation in rainfall. Another source of particular concern is our finding that poor young women are even more susceptible to being pushed into the labor market when negative rainfall deviations are experienced. In addition, we find that the rainfall deviations also affect cognitive test scores, and that the mechanism is likely through earlier departure from school, possibly combined with a decrease in school quality, rather than the psychological stress explanations posited in the literature.

Our results are robust to a range of definitions of rainfall deviations. We also conduct numerous robustness checks, including using SBU fixed effects, interacting the rainfall indicator with individuallevel variables (like being a woman), or running the estimation on specific subsamples (which exclude 
the CMs who migrated throughout the period or those living in non-agricultural households). These checks identify possible correlations between the characteristics of the CMs and rainfall variability and some heterogeneous effects.

It is important to recall that we analyze the effect of normal rainfall variability and that the long span of our analysis covers a period not characterized by exceptional rainfall events. The effects we observe could be more pronounced in case of prolonged negative shocks.

The findings in our article add to a rapidly growing literature on the role of weather shocks on a range of outcomes, including schooling and work. Although climate scientists will continue to address the causes of weather shocks and work to prevent human activity that contributes to climate change, our research also highlights the importance of mitigation efforts. Mitigation is especially important for the poor in ecologically fragile countries like Madagascar, which lack economic and social institutions that can help protect the vulnerable from climate shocks. This article, therefore, suggests the need for further research to identify programs and policies to assist households in coping with weather shocks. Asfaw and Maggio (2017) showed that social cash transfers mitigated the deleterious impact of weather shocks in Malawi. Clearly, there is a need for further work to examine how to cope with what are increasing climate and related environmental risks for vulnerable groups, but also for the population in general. It seems equally clear that policymakers need to consider efforts beyond social projection and related transfer programs. Initiatives should include better early warning systems both for catastrophic events like cyclones, as well as extreme drought and water shortages that compromise rural livelihoods and food output. Likewise, policy needs to promote agricultural practices and related practices in fragile ecosystems like in Madagascar to emphasize conservation of soils and water, prevention of deforestation, and overall, better stewardship of nature resources. Agricultural practices must consider resilience, among other paramount objectives such as productivity. And in terms of agricultural policies, 
we need to better understand the potential for policies that promote more production and dietary diversity. This may also facilitate smoothing nutrient consumption, especially in agroclimatic regions that are heavily dependent on single staple crops.

In addition, there are a range of other areas that are likely instrumental to reacting to weather shocks, such as credit markets and more robust savings institutions that will facilitate household adaptation through consumption smoothing. Labor market reforms that reduce imperfections, enabling households to both source outside labor for family enterprises and home production also, would be important, especially to the extent that the lack of access to alternative sources of labor may in part contribute to decisions for early school departures. The argument here is for a better understanding of formal as well as informal arrangements to insure households against idiosyncratic shocks, the latter including reliance on family, friends, and community networks. It is clear that a possible policy agenda on how to deal with the impact of climate and weather shocks is expansive, but inadequately explored. 


\section{References}

Alderman, H., J. Behrman, H.-P. Kohler, J.A. Maluccio, and S. Watkins. 2001. "Attrition in

Longitudinal Household Survey Data: Some Tests for Three Developing-Country Samples.

Demographic Research 5 (Article 4): 79-124. doi:10.4054/DemRes.2001.5.4

Angrist, J.D., and J.-S. Pischke. 2008. Mostly Harmless Econometrics: An Empiricist's Companion.

Princeton, NJ: Princeton University Press.

Almanza, C.H., D.E. Sahn. 2018. "Early Childbearing, School Attainment and Cognitive Skills:

Evidence from Madagascar." Demography 55 (2): 643-68.

Amare, M., N.D. Jensen, B. Shiferaw, and J.D. Cissé. 2018. “Agricultural Productivity: Implication for Rural household Consumption.” Agricultural Systems 166: 79-89.

Asfaw, S., and G. Maggio. 2017. "Gender, Weather Shocks and Welfare: Evidence from Malawi." Journal of Development Studies 54 (2): 271-91.

Aubery, F., and D.E. Sahn. 2017. "Cognitive Achievement Production in Madagascar: A Value-Added Approach.” Unpublished manuscript.

Baird, S., J. Hamory, and E. Miguel. 2008 "Tracking, Attrition and Data Quality in the Kenyan Life Panel Survey Round 1, KLPS-1.” Working paper, Center for International and Development Economics Research, University of California, Berkley. https://escholarship.org/uc/item/3cw7p1hx Bandyopadhyay, S., and E. Skoufias. 2015. "Rainfall Variability, Occupational Choice, and Welfare in Rural Bangladesh.” Review of Economics of the Household 13 (3): 589-634.

Beegle, K., R. H. Dehejia, and R. Gatti. 2006. “Child Labor and Agricultural Shocks.” Journal of Development Economics 81 (1): 80-96.

Behrman, J.R., J. Hoddinott, J.A. Maluccio, E. Soler-Hampejsek, E.L. Behrman, R. Martorell, M. Ramírez-Zea, and A.D. Stein. 2014. "What Determines Adult Cognitive Skills? Influences of Pre- 
school, School, and Post-school Experiences in Guatemala." Latin American Economic Review 23 (4). https://doi.org/10.1007/s40503-014-0004-4

Bengtsson, N. 2010. "How Responsive Is Body Weight to Transitory Income Changes? Evidence from Rural Tanzania.” Journal of Development Economics 92 (1): 53-61.

Björkman-Nyqvist, M. 2013. "Income Shocks and Gender Gaps in Education: Evidence from Uganda." Journal of Development Economics 105: 237-53.

Colmer, J. 2017. "Parental Income Uncertainty, Child Labour, and Human Capital Accumulation.” Unpublished. University of Virginia. https://drive.google.com/file/d/0B-

\section{BakBtoHwF8NXVIaW9hWDYxZ3c/view}

Das, J. and Zajonc, T., 2010. "India Shining and Bharat Drowning: Comparing Two Indian States to the Worldwide Distribution in Mathematics Achievement. "Journal of Development Economics 92 (2): $175-87$.

de Janvry, A., M. Fafchamps, and E. Sadoulet. 1991. "Peasant Household Behaviour with Missing Markets: Some Paradoxes Explained.” Economic Journal 101 (409): 1400-17.

de Janvry, A., and E. Sadoulet. 2006. "Progress in the Modeling of Rural Households' Behavior under Market Failures." In Poverty, Inequality and Development, edited by A. de Janvry and R. Kanbur, 155-81. Boston: Springer.

Dell, M., B. Jones, and B. Olken. 2014. "What Do We Learn from the Weather? The New ClimateEconomy Literature.” Journal of Economic Literature 52 (3): 740-98.

Dillon, A., K. McGee, and G. Oseni. 2015. “Agricultural Production, Dietary Diversity and Climate Variability.” Journal of Development Studies 51 (8): 976-95.

Dumas, C. 2015. "Shocks and Child Labor: The Role of Markets.” FSES Working Paper, Faculty of Economics and Social Sciences, University of Freiburg/Fribourg, Switzerland. 
Duryea, S., and M. Arends-Kuenning. 2003. "School Attendance, Child Labor and Local Labor Market Fluctuations in Urban Brazil." World Development 31 (7): 1165-78.

FAO (Food and Agriculture Organization of the United Nations). 2016. "Welfare Impacts of Climate Shocks: Evidence from Tanzania.” ESA Working Paper No. 16-04, Agricultural Development Economics Division, FAO, Rome. . 2011. Guidelines for the Preparation of Livestock Sector Reviews. Animal Production and Health Guidelines. No. 5. Rome.

Fernández-Val, I., and M. Weidner. 2016. "Individual and Time Effects in Nonlinear Panel Models with Large N, T.” Journal of Econometrics 192 (1): 291-312.

Filmer, D., and L.H. Pritchett. 2001. "Estimating Wealth Effects without Expenditure Data—or Tears: An Application to Educational Enrollments in States of India.” Demography 38 (1): 115-32.

Fitchett, J.M., and S.W. Grab. 2014. “A 66-Year Tropical Cyclone Record for South-East Africa: Temporal Trends in a Global Context." International Journal of Climatology 34 (13): 3604-15. Grajeda, R., J.R. Behrman, R. Flores, J.A. Maluccio, R. Martorell, and A.D. Stein. 2005. "The Human Capital Study 2000-04; Tracking, Data Collection, Coverage, and Attrition." Food and Nutrition Bulletin 26 (2) (Supplement 1): S15-23.

Greene, W. 2004. "The Behaviour of the Maximum Likelihood Estimator of Limited Dependent Variable Models in the Presence of Fixed Effects.” Econometrics Journal 7 (1): 98-119.

Groppo, V., and K. Kraehnert. 2017. “The Impact of Extreme Weather Events on Education.” Journal of Population Economics 30 (2): 433-72.

Henning, C.H.C.A., and A. Henningsen. 2007. "Modeling Farm Households' Price Responses in the Presence of Transaction Costs and Heterogeneity in Labor Markets."American Journal of Agricultural Economics 89 (3): 665-81. 
Hervieu, S. 2015. "Madagascar, terminus des cyclones.” Le Monde. October 10.

http://www.lemonde.fr/planete/visuel/2015/10/10/madagascar-terminus-des-

cyclones_4786327_3244.html

Hirvonen, K. 2016. “Temperature Changes, Household Consumption, and Internal Migration: Evidence from Tanzania." American Journal of Agricultural Economics 98 (4): 1230-49.

Hsiang, S. 2016. "Climate Econometrics." Annual Review of Resource Economics 8: 43-75.

Jacoby, H.G., and E. Skoufias. 1997. "Risk, Financial Markets, and Human Capital in a Developing Country." Review of Economic Studies 64 (3): 311-35.

Jayachandran, S. 2006. "Selling Labor Low: Wage Responses to Productivity Shocks in Developing Countries.” Journal of Political Economy 114 (3): 538-75.

Jensen, R. 2000. "Agricultural Volatility and Investments in Children." American Economic Review 90 (2): $399-404$.

Jessoe, K., D.T. Manning, and J.E. Taylor. 2018. "Climate Change and Labour Allocation in Rural Mexico: Evidence from Annual Fluctuations in Weather.” Economic Journal 128 (608): 230-61.

Kreft, S., D. Eckstein, L. Dorsch, and L. Fischer. 2016. "Who Suffers Most from Extreme Weather Events? Weather-related Loss Events in 2014 and 1995 to 2014." Global Climate Risk Index 2016, Briefing Paper, Germanwatch e.V., Bonn.

Levine, D., and D. Yang. 2014. “The Impact of Rainfall on Rice Output in Indonesia.” NBER Working Paper No. 20302, National Bureau of Economic Research, Cambridge, MA.

Maccini, S., and D. Yang. 2009. "Under the Weather: Health, Schooling, and Economic Consequences of Early-Life Rainfall.” American Economic Review 99 (3): 1006-26.

Mahajan, K., 2017. "Rainfall Shocks and the Gender Wage Gap: Evidence from Indian Agriculture." World Development 91: 156-72. 
Mani, A., S. Mullainathan, E. Shafir, and J. Zhao. 2013. "Poverty Impedes Cognitive Function.” Science 341 (6149): 976-80.

Mavume, A.F., L. Rydberg, M. Rouault, and J.R.E. Lutjeharms. 2009. "Climatology and Landfall of Tropical Cyclones in the South-West Indian Ocean." Western Indian Ocean Journal of Marine Science 8 (1): 15-36.

Rajaon, M.D., M.J.R. Randimbiarison, and M.M. Raherimandimby. 2015. “Les écoles résistantes aux cyclones: Etude de cas.” Fonds d'intervention pour le développement (FID), Madagascar. https://www.unisdr.org/2007/campaign/pdf/case-study-madagascar-fr.pdf

Rosenzweig, M.R., and R. Evenson. 1977. "Fertility, Schooling, and the Economic Contribution of Children of Rural India: An Econometric Analysis.” Econometrica 45 (5): 1065-79.

Sadoulet, E., and A. de Janvry. 1995. Quantitative Development Policy Analysis. Baltimore, MD: Johns Hopkins University Press.

Sesmero, J., J. Ricker-Gilbert, and A. Cook. 2018. "How Do African Farm Households Respond to Changes in Current and Past Weather Patterns? A Structural Panel Data Analysis from Malawi.” American Journal of Agricultural Economics 100 (1): 115-44.

Shah, M., and B.M. Steinberg. 2017. "Drought of Opportunities: Contemporaneous and Long-Term Impacts of Rainfall Shocks on Human Capital.” Journal of Political Economy 125 (2): 527-61.

Singh, I., L. Squire, and J. Strauss. 1986. Agricultural Household Models: Extensions, Applications, and Policy. Baltimore, MD: Johns Hopkins University Press for the World Bank.

Skoufias, E., S. Bandyopadhyay, and S. Olivieri. 2017. "Occupational Diversification as an Adaptation to Rainfall Variability in Rural India." Agricultural Economics 48 (1): 77-89.

Tiberti, L., and M. Tiberti. 2015. "Rural Policies, Price Change and Poverty in Tanzania: An Agricultural Household Model-Based Assessment.” Journal of African Economies 24 (2): 193-229. 
Tiwari, S., H.G. Jacoby, and E. Skoufias. 2017. "Monsoon Babies: Rainfall Shocks and Child Nutrition in Nepal." Economic Development and Cultural Change 65 (2): 167-88.

UNICEF (United Nations Children’s Fund). 2016. “Madagascar El Niño Drought Humanitarian Situation Report.” September 2016, UNICEF-Madagascar.

https://reliefweb.int/sites/reliefweb.int/files/resources/UNICEF\%20Madagascar\%20Humanitarian\% 20SitRep\%20-\%20Sep\%202016.pdf

Villalobos, L. 2016. "Effects of Weather on Daily School Attendance Decisions and Academic Performance in Rural Costa Rica.” Unpublished manuscript, Department of Economics, University of Gothenburg.

Walsh, R.P.D., and D.M. Lawler. 1981. "Rainfall Seasonality: Description, Spatial Patterns and Change Through Time." Weather 36 (7): 201-8. 


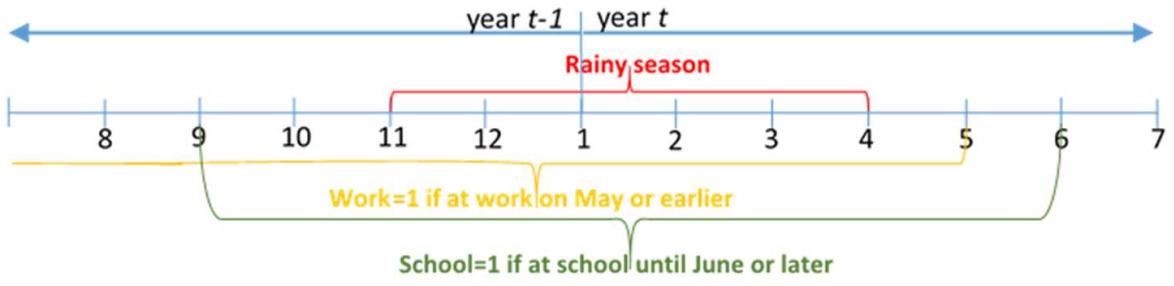

Figure 1. Timing of school, work, and rainfall variables

Notes: On the horizontal axis, we report the months of the year.

Source: Authors' elaboration. 


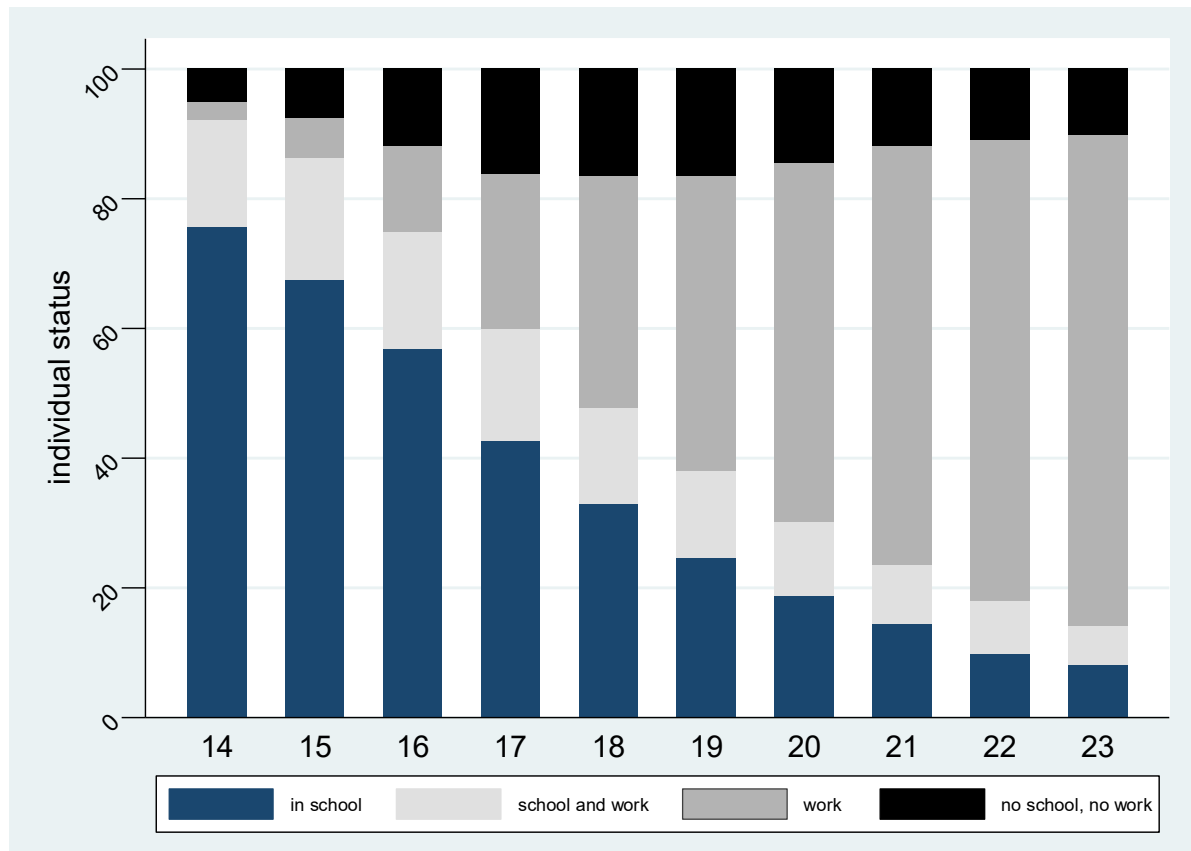

Figure 2. School-to-work transition between 14- and 23-years old (in 2004-2011), rural cohort members

Source: Authors' elaboration based on Madagascar Young Adult Survey. 

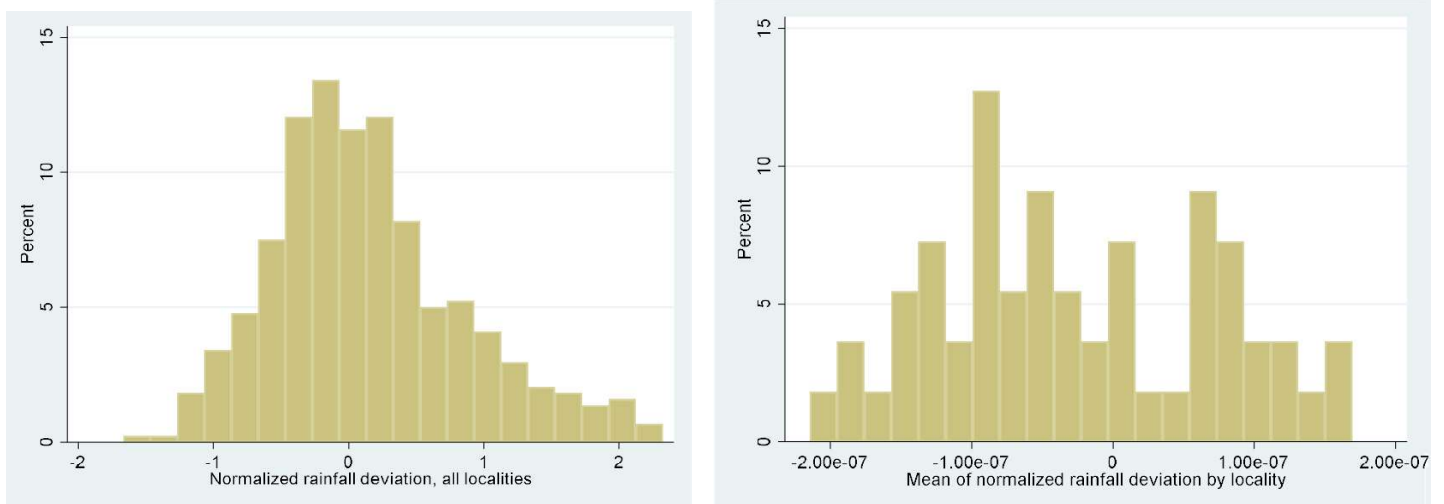

Figure 3. Distribution of rainfall deviations (left panel) and distribution of the mean of rainfall deviation by satellite-based unit (right panel) in baseline rural communities

Source: Authors' elaboration from the Madagascar Young Adult Survey. 

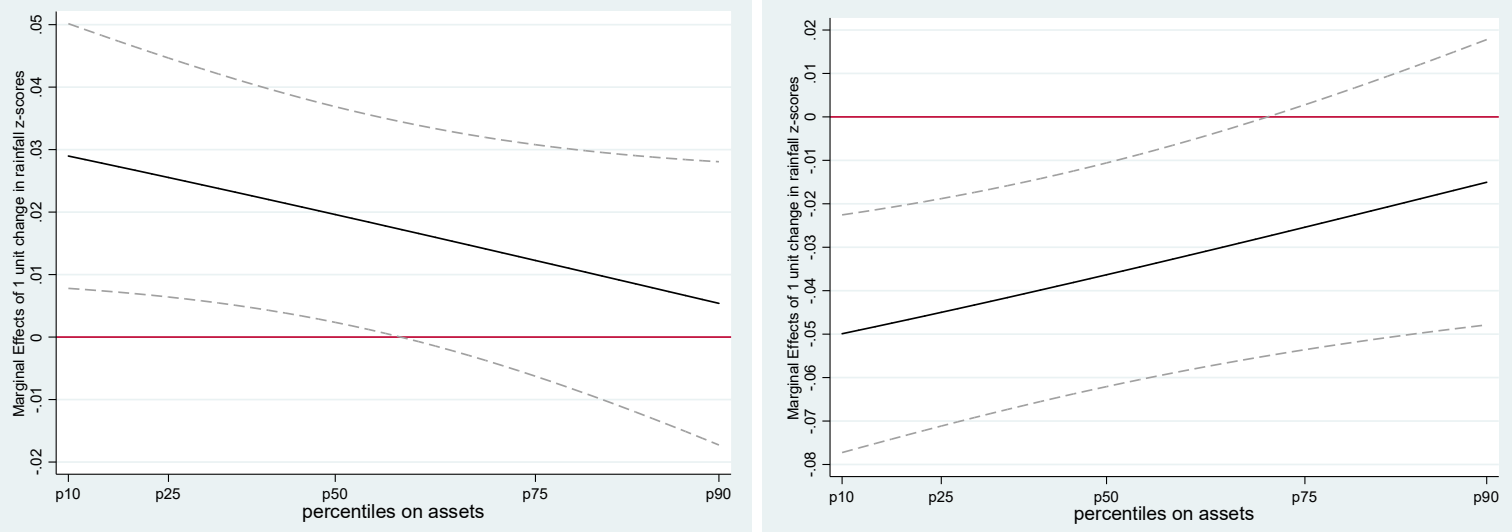

Figure 4. Marginal effects of rainfall deviations on the likelihood of schooling (left panel) and working (right panel)

Notes: Dashed grey curves identify the confidence intervals.

Source: Authors' elaboration based on specification (4) in table 1. 
Table 1. Effects of Rainfall on School and Work Decisions, Main Specifications
(1)
(2)
(3)
(4)

Equation: School

Rainfall (6 months)

$$
\begin{array}{llll}
0.056^{*} & 0.098^{* *} & 0.108^{* * *} & 0.111^{* * *} \\
(0.031) & (0.040) & (0.039) & (0.041)
\end{array}
$$

Assets

$$
0.001 * * * \quad 0.010^{* * *} \quad 0.010^{* * *} \quad 0.010^{* * *}
$$$$
(0.003) \quad(0.003) \quad(0.003) \quad(0.003)
$$

Rainfall x Assets

$$
\begin{array}{ccc}
-0.002 * & -0.002 * & -0.002 * \\
(0.001) & (0.001) & (0.001)
\end{array}
$$

Cyclones

$$
\begin{array}{ll}
-0.237 * * * & -0.384 * * * \\
0.096 & (0.097)
\end{array}
$$

Lagged rainfall

0.054

$(0.044)$

Lagged rainfall x Assets

$-0.001$

$(0.001)$

Equation: Work

(1)

(2)

(3)

(4)

Rainfall (6 months)

$$
\begin{array}{llll}
-0.101 * * & -0.146 * * * & -0.153 * * * & -0.163 * * * \\
(0.040) & (0.047) & (0.047) & (0.045)
\end{array}
$$

Assets

$$
\begin{array}{llll}
-0.010 * * * & -0.010^{* * *} & -0.010 * * * & -0.010 * * * \\
(0.004) & (0.003) & (0.003) & (0.003)
\end{array}
$$

Rainfall x Assets

$$
\begin{array}{lll}
0.002 * & 0.002 * & 0.003 * * \\
(0.001) & (0.001) & (0.001)
\end{array}
$$


Cyclones

Lagged rainfall

Lagged rainfall x Assets

$$
\begin{array}{ll}
0.237 * & 0.266 * * \\
(-0.130) & (0.132)
\end{array}
$$

$$
-0.176^{* * *}
$$

(0.046)

$0.002 * *$

$(0.001)$

$\begin{array}{llll}\text { Observations } & 8,600 & 8,600 & 8,600\end{array}$

Notes: Specification (1) includes all variables shown in table A.4 except for the interaction between rainfall and assets; (2) corresponds to the specification in table A.4 (this is our base specification); and (3) as in (2) plus dummy variable for cyclones; (4) as in (3) plus lagged ( $t-1$ ) rainfall variable. Standard errors in parenthesis. $* * * * *$, and $*$ stand for significant at $1 \%, 5 \%$ and $10 \%$ level.

Source: Authors' elaboration from the Madagascar Young Adult Survey and EPSPAM. 
Table 2. Marginal Effects of Cyclones, Rainfall, and Lagged Rainfall on School and Work Decisions, at Different Assets Levels

\begin{tabular}{|c|c|c|c|c|c|c|c|c|}
\hline & School & Work & School & Work & School & Work & School & Work \\
\hline & Assets p25 & & Assets p50 & & Assets p75 & & Assets mean & \\
\hline \multirow[t]{2}{*}{ Lagged rainfall } & 0.018 & $-0.061 * * *$ & 0.015 & $-0.052 * * *$ & 0.011 & $-0.041 * *$ & 0.014 & $-0.050 * *$ \\
\hline & $(0.015)$ & $(0.017)$ & $(0.013)$ & $(0.017)$ & $(0.014)$ & $(0.018)$ & $(0.013)$ & $(0.017)$ \\
\hline \multirow[t]{2}{*}{ Rainfall } & $0.036 * * *$ & $-0.055 * * *$ & $0.027 * *$ & $-0.044 * * *$ & 0.017 & $-0.031 *$ & $0.025 * *$ & $-0.041 * *$ \\
\hline & $(0.012)$ & $(0.016)$ & $(0.012)$ & $(0.016)$ & $(0.13)$ & $(0.017)$ & $(0.127)$ & $(0.016)$ \\
\hline \multirow[t]{2}{*}{ Cyclones } & $-0.147 * * *$ & $-0.102 * * *$ & $-0.150 * * *$ & $0.104^{* *}$ & $-0.152 * * *$ & $0.105 * *$ & $-0.152 * * *$ & $0.105 * *$ \\
\hline & $(0.035)$ & $(0.048)$ & $(0.036)$ & $(0.049)$ & $(0.037)$ & $(0.051)$ & $(0.036)$ & $(0.050)$ \\
\hline
\end{tabular}

Notes: Standard errors in parenthesis. $* * *, * *$, and $*$ stand for significant at 1\%, 5\%, and $10 \%$ level.

Source: Authors' elaboration from the Madagascar Young Adult Survey and EPSPAM, based on table 1 results, specification (4). 
Table 3. Effects of Rainfall on School and Work Decisions, Robustness Checks (Subpopulation and Fixed Effects)
(2)
(5)
(6)
(7)
(8)

\begin{tabular}{|c|c|c|c|c|c|}
\hline \multicolumn{6}{|l|}{ Equation: School } \\
\hline \multirow[t]{2}{*}{ Rainfall (6 months) } & $0.098 * *$ & $0.094 * *$ & $0.081^{*}$ & $0.100 * *$ & $0.087 * *$ \\
\hline & $(0.040)$ & $(0.043)$ & $(0.044)$ & $(0.042)$ & $(0.041)$ \\
\hline \multirow[t]{2}{*}{ Assets } & $0.010 * * *$ & $0.010 * * *$ & $0.008 * *$ & $0.010 * * *$ & $0.010 * *$ \\
\hline & $(0.003)$ & $(0.003)$ & $(0.004)$ & $(0.004)$ & $(0.004)$ \\
\hline \multirow[t]{2}{*}{ Rainfall x Assets } & $-0.002 *$ & $-0.002 *$ & -0.000 & $-0.003^{*}$ & $-0.002 *$ \\
\hline & $(0.001)$ & $(0.001)$ & $(0.001)$ & $(0.001)$ & $(0.001)$ \\
\hline \multirow[t]{2}{*}{ Woman (dummy) } & $-0.218 * * *$ & $-0.219 * * *$ & $-0.169 * *$ & $-0.178 * * *$ & $-0.191 * * *$ \\
\hline & $(0.065)$ & $(0.065)$ & $(0.073)$ & $(0.069)$ & $(0.073)$ \\
\hline \multirow[t]{2}{*}{ Rainfall x Woman } & & 0.008 & & & \\
\hline & & $(0.039)$ & & & \\
\hline SBUs fixed effects & no & no & no & no & Yes \\
\hline Equation: Work & (2) & (5) & (6) & (7) & (8) \\
\hline \multirow[t]{2}{*}{ Rainfall (6 months) } & $-0.146^{* * *}$ & $-0.111 * *$ & $-0.136^{* * *}$ & $-0.132 * * *$ & $-0.085^{*}$ \\
\hline & $(0.047)$ & $(0.047)$ & $(0.051)$ & $(0.050)$ & $(0.046)$ \\
\hline \multirow[t]{2}{*}{ Assets } & $-0.010^{* * *}$ & $-0.010 * * *$ & $-0.009 * * *$ & $-0.006^{*}$ & $-0.007 * *$ \\
\hline & $(0.003)$ & $(0.003)$ & $(0.003)$ & $(0.004)$ & $(0.003)$ \\
\hline \multirow[t]{2}{*}{ Rainfall x Assets } & $0.002 *$ & $0.002 *$ & 0.001 & 0.002 & 0.002 \\
\hline & $(0.001)$ & $(0.001)$ & $(0.002)$ & $(0.001)$ & $(0.001)$ \\
\hline \multirow[t]{2}{*}{ Woman (dummy) } & 0.015 & 0.021 & 0.030 & 0.023 & -0.006 \\
\hline & $(0.064)$ & $(0.057)$ & $(0.064)$ & $(0.063)$ & $(0.067)$ \\
\hline Rainfall x Woman & & $-0.066^{* *}$ & & & \\
\hline
\end{tabular}


$(0.034)$

\begin{tabular}{llllll} 
SBUs fixed effects & no & no & no & no & yes \\
\hline Observations & 8,600 & 8,600 & 7,355 & 7,720 & 8,600
\end{tabular}

Notes: For specification (2), see the notes to table 1; (5) as in (2) plus interaction between rainfall and woman; (6) as in (2) but by excluding migrants (see text for definition); (7) as in (2) but by excluding nonagricultural households (see text for definition); (8) as in (2) plus SBUs fixed effects. Standard errors in parenthesis. ***, **, and * stand for significant at $1 \%, 5 \%$, and $10 \%$ level.

Source: Authors' elaboration from the Madagascar Young Adult Survey and EPSPAM. 
Table 4. Effects of Rainfall on School and Working Decisions, with Different Definitions and Measures of Rainfall

\begin{tabular}{|c|c|c|c|c|c|c|c|c|c|c|c|c|}
\hline \multirow{2}{*}{$\begin{array}{l}\text { Equation } \\
\text { Specification: }\end{array}$} & \multicolumn{6}{|l|}{ School } & \multicolumn{6}{|l|}{ Work } \\
\hline & (2) & (9) & (10) & (11) & (12) & (13) & (2) & (9) & $(10)$ & (11) & (12) & (13) \\
\hline \multirow[t]{2}{*}{ Rainfall } & $0.098 * *$ & & & & $0.106^{* * *}$ & $0.099 * *$ & $-0.146^{* * *}$ & & & & $-0.169 * * *$ & $-0.138 * * *$ \\
\hline & $(0.040)$ & & & & $(0.040)$ & $(0.041)$ & $(0.047)$ & & & & $(0.049)$ & $(0.048)$ \\
\hline \multirow[t]{2}{*}{ Assets } & $0.010 * * *$ & $0.009 * * *$ & $0.028 * * *$ & $0.008 * * *$ & -0.004 & $0.010 * * *$ & $-0.010 * * *$ & $-0.009 * * *$ & $-0.024 * * *$ & $-0.008 * * *$ & 0.007 & $-0.010 * * *$ \\
\hline & $(0.003)$ & $(0.003)$ & $(0.005)$ & $(0.003)$ & $(0.011)$ & $(0.003)$ & $(0.003)$ & $(0.003)$ & $(0.007)$ & $(0.003)$ & $(0.008)$ & $(0.003)$ \\
\hline \multirow[t]{2}{*}{ Rainfall x Assets } & $-0.002 *$ & & & & $-0.003 * *$ & $-0.002 *$ & $0.002 *$ & & & & $0.003 * *$ & $0.002 *$ \\
\hline & $(0.001)$ & & & & $(0.001)$ & $(0.001)$ & $(0.001)$ & & & & $(0.001)$ & $(0.001)$ \\
\hline \multicolumn{13}{|c|}{ Rainfall categories (ref: $<-1$ ) } \\
\hline \multirow[t]{2}{*}{ Cat2: $>-1 \&<0$} & & & $0.534 * * *$ & & & & & & $-0.484 * * *$ & & & \\
\hline & & & $(0.115)$ & & & & & & $(0.165)$ & & & \\
\hline \multirow[t]{2}{*}{ Cat3: $>0 \&<1$} & & & $0.610 * * *$ & & & & & & $-0.535 * * *$ & & & \\
\hline & & & $(0.115)$ & & & & & & $(0.171)$ & & & \\
\hline \multirow[t]{2}{*}{ Cat4: $>1 \&<2$} & & & $0.626^{* * *}$ & & & & & & $-0.792 * * *$ & & & \\
\hline & & & $(0.131)$ & & & & & & $(0.212)$ & & & \\
\hline \multirow[t]{2}{*}{ Cat5: $>2$} & & & $0.640 * *$ & & & & & & $-0.717 * *$ & & & \\
\hline & & & $(0.250)$ & & & & & & $(0.312)$ & & & \\
\hline \multirow[t]{2}{*}{ Cat 2 x Assets } & & & $-0.019 * * *$ & & & & & & $0.016 * *$ & & & \\
\hline & & & $(0.005)$ & & & & & & $(0.007)$ & & & \\
\hline
\end{tabular}




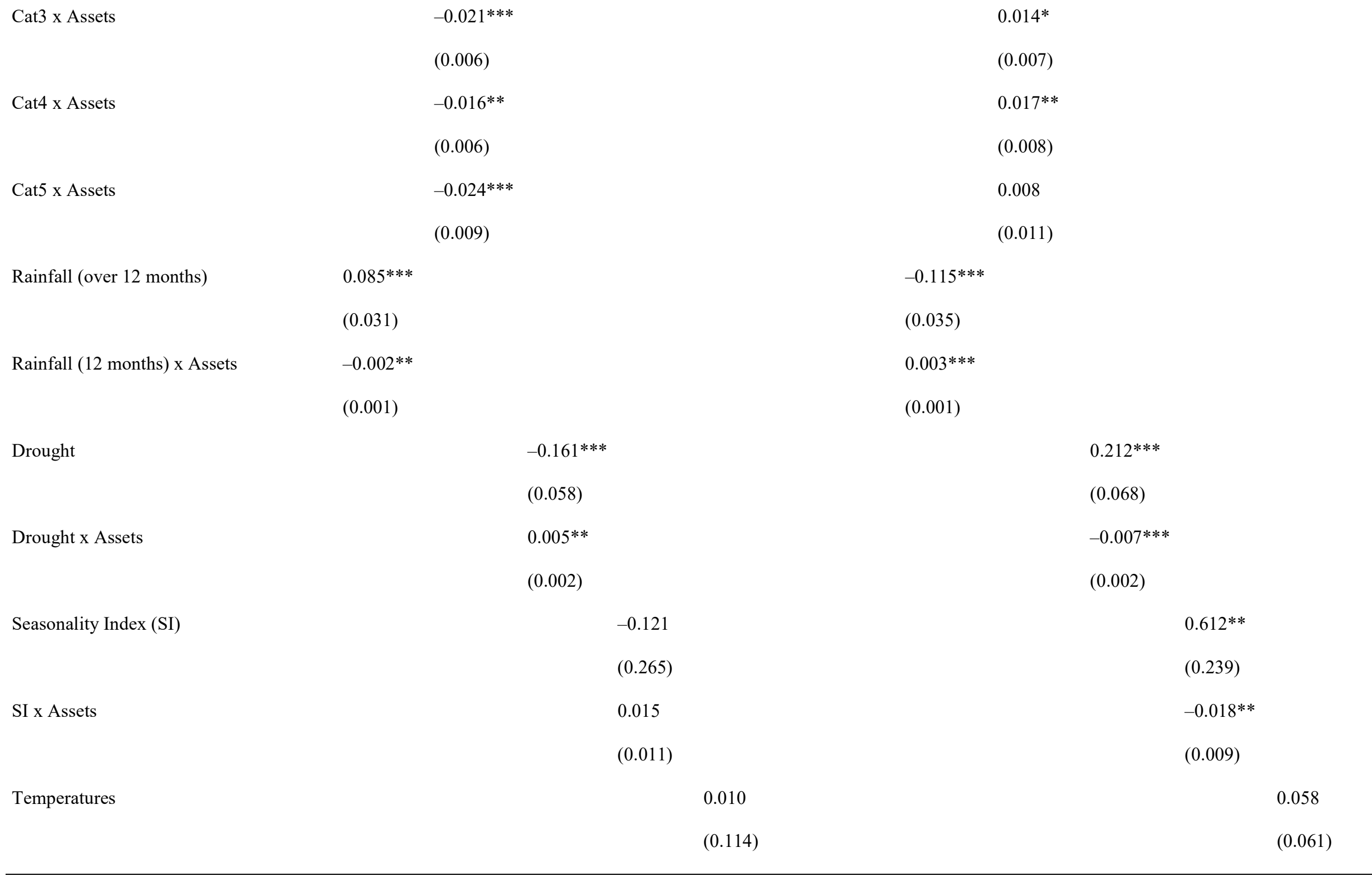




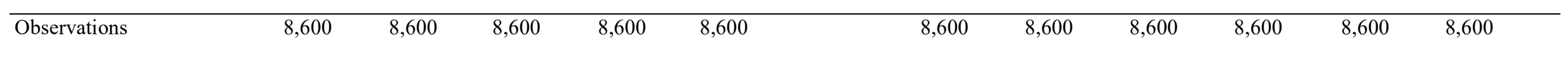

Notes: For specification (2), see the note to Table 3; (9) as in (2) but with rainfall estimated over 12 months (instead of over 6 months); (10) as in (2)

but with rainfall variable defined in 5 categories (see footnote 19 for their definition) (instead of a continuous rainfall variable); (11) as in (2) but with a binary variable identifying drought (instead of a continuous rainfall variable); (12) as in (2) plus a seasonality index and the interaction between the seasonality index and the assets; (13) as in (2) plus the temperature variable. Standard errors in parenthesis. ***,**, and * stand for significant at $1 \%, 5 \%$, and $10 \%$ level.

Source: Authors' elaboration from the Madagascar Young Adult Survey and ESPAM. 
Table 5. Effects of Rainfall on Math, French and Combined Test Scores, 2011

\begin{tabular}{|c|c|c|c|c|c|}
\hline \multirow[t]{2}{*}{ OUTCOMES } & \multicolumn{3}{|c|}{ MF } & \multirow{2}{*}{$\begin{array}{l}\text { MTO } \\
\text { School }\end{array}$} & \multirow{2}{*}{$\begin{array}{c}\text { FR } \\
\text { School }\end{array}$} \\
\hline & Full & No School & School & & \\
\hline \multirow[t]{2}{*}{ Rainfall (6months) } & $0.326 * * *$ & 0.192 & $0.370 * * *$ & $0.530 * * *$ & $0.314 * *$ \\
\hline & $(0.097)$ & $(0.121)$ & $(0.136)$ & $(0.132)$ & $(0.130)$ \\
\hline \multirow[t]{2}{*}{ Rainfall x 2011 Assets } & -0.030 & -0.077 & 0.105 & 0.001 & 0.041 \\
\hline & $(0.074)$ & $(0.088)$ & $(0.080)$ & $(0.081)$ & $(0.069)$ \\
\hline \multirow[t]{2}{*}{2011 Assets } & $0.307 * * *$ & $0.282 * * *$ & -0.004 & -0.090 & 0.095 \\
\hline & $(0.048)$ & $(0.054)$ & $(0.086)$ & $(0.078)$ & $(0.068)$ \\
\hline \multirow[t]{2}{*}{ Lagged Rainfall } & 0.019 & -0.032 & 0.179 & $0.314 * *$ & 0.031 \\
\hline & $(0.086)$ & $(0.092)$ & $(0.136)$ & $(0.129)$ & $(0.129)$ \\
\hline \multirow[t]{2}{*}{ Lagged Rainfall x 2011 Assets } & -0.003 & -0.020 & $-0.231 *$ & $-0.222 *$ & -0.106 \\
\hline & $(0.072)$ & $(0.084)$ & $(0.123)$ & $(0.112)$ & $(0.095)$ \\
\hline Observations & 941 & 743 & 198 & 198 & 198 \\
\hline R-squared & 0.471 & 0.436 & 0.485 & 0.420 & 0.503 \\
\hline
\end{tabular}

Notes: Robust standard errors in parentheses. Full = estimations run on the full sample with non-missing test scores; no school = estimations run only on those not going to school; school $=$ estimations run only on those going to school; $\mathrm{MF}=$ combined Math and French; MTO = oral math; FR $=$ written French; $* * * p<0.01, * * p<0.05, * p<0.1$ Source: Authors' elaboration from the Madagascar Young Adult Survey and ESPAM. 
Title: AJAE appendix for The Role of Weather on Schooling and Work of Young Adults in Madagascar

Authors: Francesca Marchetta, David Sahn and Luca Tiberti

Date: March 5, 2019

Note: The material contained herein is supplementary to the article named in the title and published in the American Journal of Agricultural Economics (AJAE). 


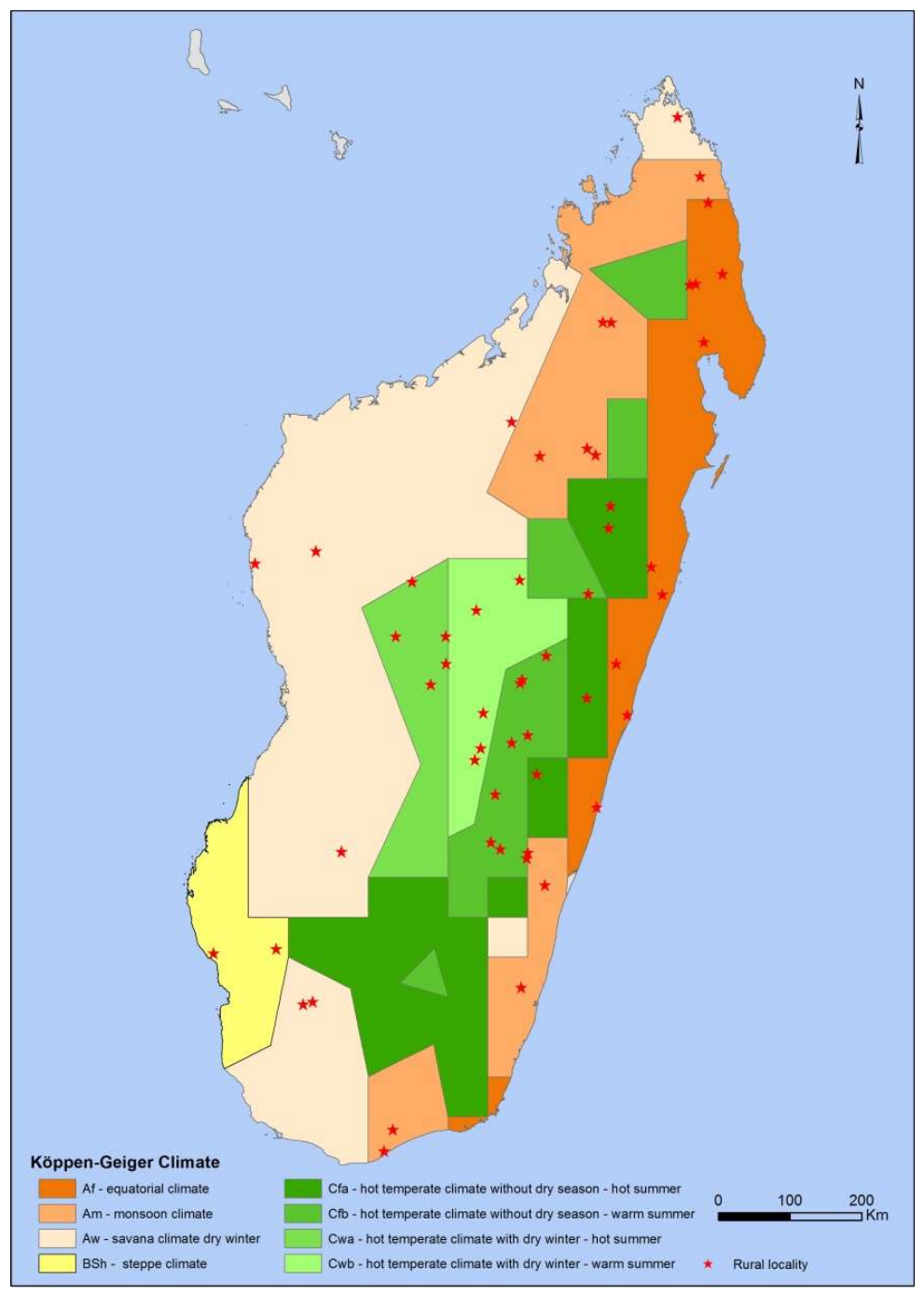

Figure A.1. Climatic zones, Köppen-Geiger climate classification system

Notes: 1. Af. Equatorial rainforest, fully humid; 2. Am. Equatorial monsoon; 3. Aw. Equatorial savannah with dry winter; 4. Bsh. Steppe climate (hot steppe); 5. Cfa. Warm temperate, fully humid (hot summer); 6. Cfb. Warm temperate, fully humid (warm summer); 7. Cwa. Warm temperate, dry winter (hot summer); 8. Cwb. Warm temperate, dry winter (warm summer).

Source: Authors' elaboration from Kottek, M., J. Grieser, C. Beck, B. Rudolf, and F. Rubel. 2006. "World Map of the Köppen-Geiger Climate Classification Updated." Meteorologische Zeitschrift 15 (3): 259-63. 


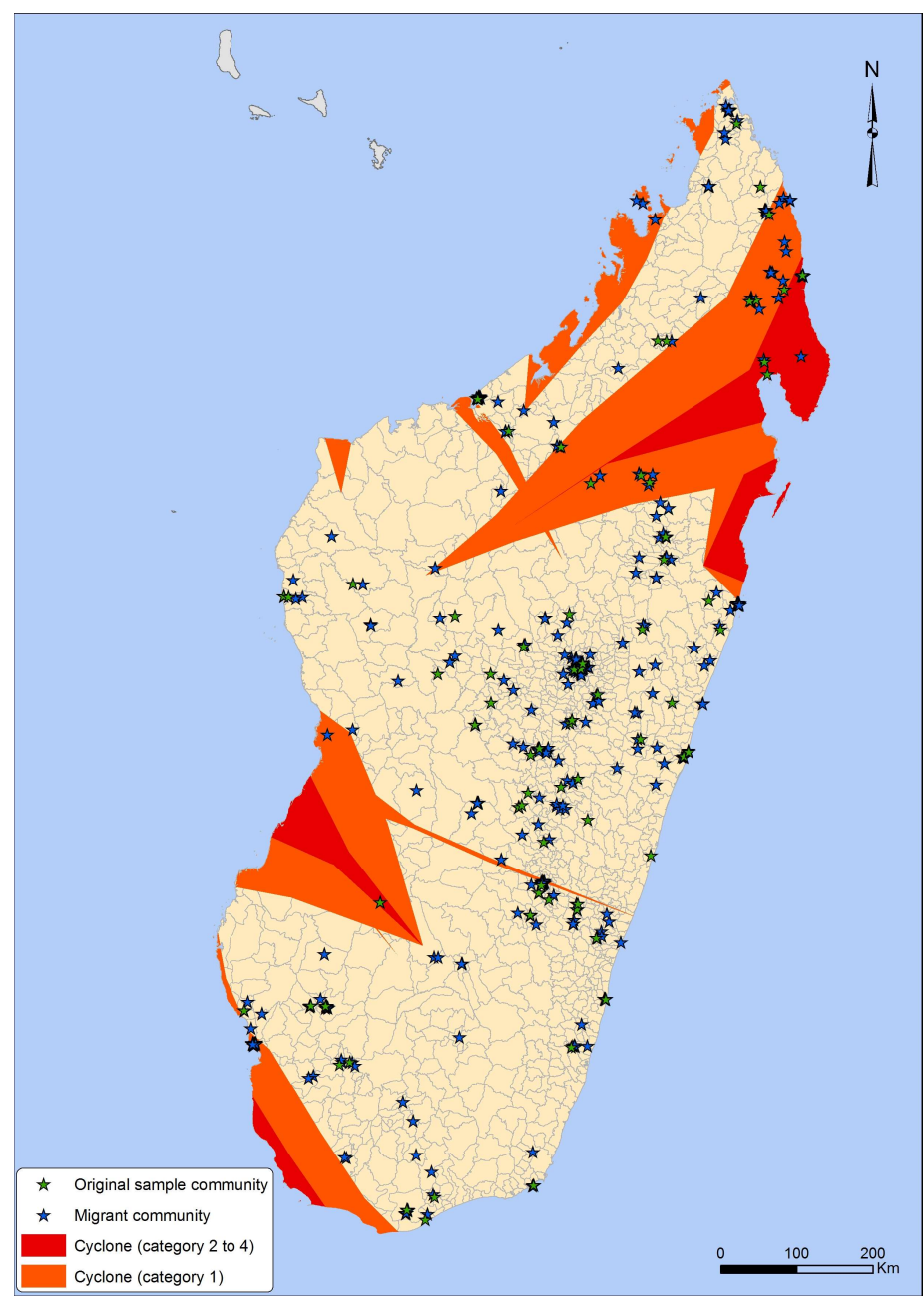

Figure A.2. Cyclones having hit sample communities over the period 2004 to 2011 Notes: Green stars indicate the original sample communities, while blue stars indicate the communities where cohort members who migrated moved.

Source: Authors' elaboration from the Global Risk Data Platform and Madagascar Young Adult Survey. 

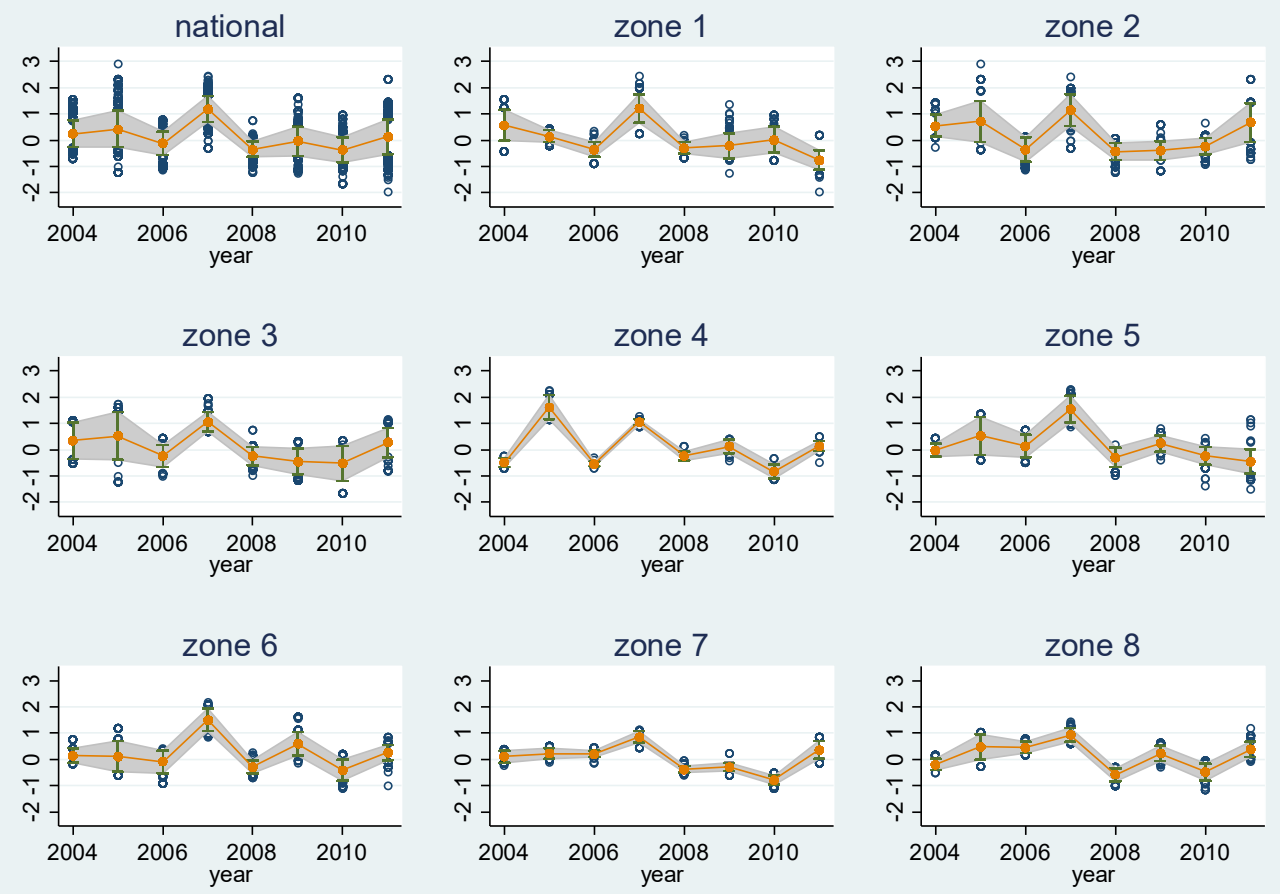

Figure A.3. Rainfall deviation from the long-term, national mean, and by climatic zones (2004-2011)

Notes: For the definition of climatic zones, see figure A.1.

Source: Authors' estimation based on African Rainfall Climatology, version 2, of the National Oceanic and Atmospheric Administration. 
Table A.1. Descriptive Statistics

\begin{tabular}{lcccc}
\hline Time-varying characteristics & Mean & $S D$ & Mean & $S D$ \\
& $(2004)$ & $(2004)$ & $(2011)$ & $(2011)$ \\
\hline Age (years) & 14.85 & 0.80 & 21.87 & 0.80 \\
Father's shock & 7.72 & 0.27 & 18.70 & 0.39 \\
Mother's shock & 5.77 & 0.23 & 12.56 & 0.33 \\
Father works & 91.26 & 0.28 & 81.30 & 0.39 \\
Mother works & 90.23 & 0.30 & 86.23 & 0.34 \\
CM lives in a new household & 1.40 & 0.12 & 46.51 & 0.50 \\
Brothers less than 18 years old (number) & 0.60 & 1.03 & 0.41 & 0.84 \\
Sisters less than 18 years old (number) & 0.53 & 0.94 & 0.40 & 0.83 \\
Migrant & 3.72 & 0.19 & 28.93 & 0.45 \\
Middle school in village & 72.00 & 0.45 & 78.33 & 0.41 \\
High school in village & 20.93 & 0.41 & 45.40 & 0.50 \\
\hline Time-invariant characteristics & Mean & & SD \\
\hline Female & 50.70 & & 0.50 \\
Age at school entry (years) & 6.95 & & 1.81 \\
Father has no education & 48.84 & & 0.50 \\
Father has completed primary & 17.77 & & 0.38 \\
Father has completed college & 33.40 & & 0.47 \\
Mother has no education & 59.72 & & 0.49 \\
Mother has completed primary & 24.00 & & 0.43 \\
Mother has completed college & 16.28 & & 0.37 \\
\hline
\end{tabular}


Table A.1. Descriptive Statistics continued

\begin{tabular}{lcc}
\hline Time-invariant characteristics & Mean & $S D$ \\
\hline Land type, interior plain & 12.47 & 0.33 \\
Land type, hill & 46.79 & 0.50 \\
Land type, plateau & 15.81 & 0.37 \\
Land type, valley & 12.47 & 0.33 \\
Land type, others & 2.42 & 0.15 \\
Paved road in village & 13.02 & 0.34 \\
\hline Number of observations & & 1,075 \\
\hline Standardized test scores (in 2011) & -0.11 & 0.90 \\
\hline MTO (oral math) & -0.11 & 0.94 \\
MTE (written math) & -0.14 & 0.91 \\
FR (written French) & -0.13 & 0.95 \\
MF (combined MTO, MTE and FR) & \\
\hline
\end{tabular}

Notes: If not specified differently, variables are expressed in percentages. Variables in italic are not included as control variables in the models. The questionnaire asks CMs the following question: "Did your father (your mother) have any illness or disability, or an injury during the last seven years (since 2004), which prevented him (her) from working or carrying on business for a month or more?" The number of observations for the test scores is slightly reduced because of a few missing values and varies between 957 and 982 .

Source: Authors' elaboration from the Madagascar Young Adult Survey and EPSPAM. 
Table A.2. Climatic Zones

\begin{tabular}{lll}
\hline Climatic zones & $\begin{array}{l}2004 \\
\text { (percentage) }\end{array}$ & $\begin{array}{l}2011 \\
\text { (percentage) }\end{array}$ \\
\hline 1. Equatorial rainforest, fully humid & 15.26 & 16.19 \\
2. Equatorial monsoon & 19.16 & 16.74 \\
3. Equatorial savannah with dry winter & 12.84 & 14.23 \\
4. Steppe climate (hot steppe) & 4.00 & 4.00 \\
5. Warm temperate, fully humid (hot summer) & 7.44 & 7.91 \\
6. Warm temperate, fully humid (warm summer) & 20.93 & 19.07 \\
7. Warm temperate, dry winter (hot summer) & 11.63 & 10.98 \\
8. Warm temperate, dry winter (warm summer) & 8.74 & 10.88
\end{tabular}

Source: Authors' elaboration from the Madagascar Young Adult Survey based on 1,075 observations. 
Table A.3. Cohort Members Hit by Cyclones, in \%

\begin{tabular}{lll}
\hline Year & $\begin{array}{l}\% \text { CM hit by at least a tropical } \\
\text { storm or a tropical cyclone }\end{array}$ & $\begin{array}{l}\% \text { CM hit by at least a tropical } \\
\text { cyclone strength } \geq 1\end{array}$ \\
\hline 2004 & 64.09 & 14.70 \\
2005 & 10.60 & 0.09 \\
2006 & 28.84 & 0.09 \\
2007 & 27.72 & 2.14 \\
2008 & 37.86 & 0.00 \\
2009 & 26.95 & 1.95 \\
2010 & 2.14 & 0.00 \\
2011 & 3.91 & 0.00 \\
\hline
\end{tabular}

Source: Authors' elaboration from the Global Risk Data Platform and Madagascar Young Adult Survey, based on 1,075 observations. 
Table A.4. Full Specification of the Base Model

\begin{tabular}{|c|c|c|}
\hline Equations & School & Work \\
\hline \multirow[t]{2}{*}{ If $\mathrm{CM}$ is a girl } & $-0.210^{* * *}$ & 0.011 \\
\hline & $(0.065)$ & $(0.057)$ \\
\hline \multirow[t]{2}{*}{ Age at school entry } & -0.026 & 0.024 \\
\hline & $(0.018)$ & $(0.020)$ \\
\hline \multirow[t]{2}{*}{ If CM lives in a new household } & $-0.286^{* * *}$ & 0.087 \\
\hline & $(0.095)$ & $(0.075)$ \\
\hline \multirow[t]{2}{*}{ Number of child siblings, boys } & 0.003 & -0.013 \\
\hline & $(0.029)$ & $(0.039)$ \\
\hline \multirow[t]{2}{*}{ Number of child siblings, girls } & 0.002 & $0.092 * *$ \\
\hline & $(0.036)$ & $(0.038)$ \\
\hline \multirow[t]{2}{*}{ If father experienced any illness or death } & -0.158 & 0.096 \\
\hline & $(0.105)$ & $(0.124)$ \\
\hline \multirow[t]{2}{*}{ If mother experienced any illness or death } & -0.128 & $0.298 * *$ \\
\hline & $(0.126)$ & $(0.144)$ \\
\hline \multirow[t]{2}{*}{ If father works } & -0.095 & 0.032 \\
\hline & $(0.108)$ & $(0.117)$ \\
\hline \multirow[t]{2}{*}{ If mother works } & -0.036 & $0.301 * *$ \\
\hline & $(0.121)$ & $(0.121)$ \\
\hline \multirow[t]{2}{*}{ Number of secondary schools (cycle 1) in the community } & $0.176^{* *}$ & 0.009 \\
\hline & $(0.082)$ & $(0.101)$ \\
\hline \multirow[t]{2}{*}{ Number of secondary schools (cycle 2 ) in the community } & 0.107 & $-0.219^{*}$ \\
\hline & $(0.081)$ & $(0.133)$ \\
\hline \multirow[t]{2}{*}{ If community has access to a paved road } & 0.091 & 0.132 \\
\hline & $(0.108)$ & $(0.131)$ \\
\hline
\end{tabular}


Table A.4. Full Specification of the Base Model continued

\begin{tabular}{lcc}
\hline Equations & School & Work \\
\hline If the household had land in 2004 & $0.165^{* *}$ & $0.113^{*}$ \\
Rainfall deviation (6 months) & $(0.071)$ & $(0.067)$ \\
& $0.098^{* *}$ & $-0.146^{* * *}$ \\
Assets in 2004 & $(0.040)$ & $(0.047)$ \\
& $0.010^{* * *}$ & $-0.010^{* * *}$ \\
Rainfall deviation x Assets & $(0.003)$ & $(0.003)$ \\
Control for (dummies): & $-0.002^{*}$ & $0.002^{*}$ \\
Age of CMs & & \\
Father's education & Yes & Yes \\
Mother's education & Yes & Yes \\
Year (2004 to 2011) & Yes & Yes \\
Climatic zone & Yes & Yes \\
Land type & Yes & Yes \\
\hline Arctanh( $\rho$ ) & Yes & Yes \\
\hline Observations & $-0.579^{* * *}$ & $(0.058)$ \\
\hline Notes: Standard & 8,600 & \\
\hline
\end{tabular}

Notes: Standard errors in parenthesis. ${ }^{* * *},{ }^{* *}$, and $*$ stand for significant at $1 \%, 5 \%$, and $10 \%$ level.

Source: Authors' estimation from the Madagascar Young Adult Survey and ESPAM.

Table A.5. Average Precipitation (in $\mathrm{mm}$ ) and

Precipitation around One Standard Deviation of

Rainfall between November and April, National and

by Climatic Zones

\begin{tabular}{lccc}
\hline Zone & Average & 1 z-score & 0 z-score \\
\hline 1 & 1175.389 & 2166.787 & 994.8435
\end{tabular}




$\begin{array}{llll}2 & 1070.435 & 1783.585 & 964.6864 \\ 3 & 842.5096 & 1227.292 & 725.5471 \\ 4 & 510.2336 & 574.7544 & 390.2637 \\ 5 & 1113.622 & 1225.844 & 979.7858 \\ 6 & 1065.659 & 1312.056 & 925.751 \\ 7 & 1321.616 & 1618.008 & 1219.17 \\ 8 & 1210.272 & 1496.411 & 1074.956\end{array}$

$\begin{array}{llll}\text { National } & 1077.534 & 1423.665 & 946.4648\end{array}$

Source: Authors' estimation based on the African Rainfall Climatology, version 2, of the National Oceanic and Atmospheric Administration. 
Table A.6. Effects of the Long-term Mean of Variables Measuring Precipitation on Normalized Rainfall Deviation

\begin{tabular}{ll}
\hline Long-term mean of rainfall variables & Coefficient \\
\hline Mean of annual precipitation, station data & $-1.92 \times 10^{-10}$ \\
& $(0.0003211)$ \\
Mean of annual precipitation, station data, normalized & $2.06 \times 10^{-8}$ \\
& $(0.4833675)$ \\
Mean of November to April precipitation, station data & $2.60 \times 10^{-10}$ \\
Mean of November to April precipitation, station data, normalized & $(0.00054)$ \\
& $-2.54 \times 10^{-7}$ \\
Mean of November to April precipitation, satellite data & $(0.391222)$ \\
& $-2.14 \times 10^{-10}$ \\
Mean of annual precipitation, satellite data & $(0.0004376)$ \\
& $1.49 \times 10^{-10}$ \\
Mean of annual precipitation, satellite data, normalized & $(0.0002896)$ \\
Constant & 0.0523209 \\
& $(236733.1)$ \\
\hline Observations & $4.65 \times 10^{-9}$ \\
\hline
\end{tabular}

Notes: Standard errors in parenthesis. Means are calculated over the period 19922012. The numbers of observations is given by the 55 baseline rural sample communities multiplied by the 21 number of years from 1992 to 2012 . 
Table A.7. Bivariate Probit Model Compared to the Linear Probability Model and Probit Models.

\begin{tabular}{lcccccc}
\hline & \multicolumn{2}{c}{ LPM } & \multicolumn{2}{c}{ Bivariate } & \multicolumn{2}{c}{ Probit } \\
\hline Outcomes & School & Work & School & Work & School & Work \\
\hline Rainfall (6 months) & $0.029^{* *}$ & $-0.036^{* * *}$ & $0.111^{* * *}$ & $-0.163^{* * *}$ & $0.092^{* *}$ & $-0.156^{* * *}$ \\
& $(0.012)$ & $(0.013)$ & $(0.041)$ & $(0.045)$ & $(0.040)$ & $(0.046)$ \\
Rainfall x Assets & -0.001 & $0.001^{* *}$ & $-0.002^{*}$ & $0.003^{* *}$ & -0.002 & $0.003^{* *}$ \\
& $(0.000)$ & $(0.000)$ & $(0.001)$ & $(0.001)$ & $(0.001)$ & $(0.001)$ \\
Assets & $0.003^{* * *}$ & $-0.002^{* * *}$ & $0.010^{* * *}$ & $-0.011^{* * *}$ & $0.010^{* * *}$ & $-0.011^{* * *}$ \\
& $(0.001)$ & $(0.001)$ & $(0.003)$ & $(0.003)$ & $(0.003)$ & $(0.003)$ \\
Lagged Rainfall & $0.020^{*}$ & $-0.036^{* * *}$ & 0.054 & $-0.176^{* * *}$ & 0.040 & $-0.173^{* * *}$ \\
& $(0.011)$ & $(0.013)$ & $(0.044)$ & $(0.046)$ & $(0.041)$ & $(0.045)$ \\
Lagged Rainfall x Assets & $-0.001 *$ & $0.001 * *$ & -0.001 & $0.003^{* *}$ & -0.001 & $0.002^{*}$ \\
& $(0.000)$ & $(0.000)$ & $(0.001)$ & $(0.001)$ & $(0.001)$ & $(0.001)$ \\
Cyclones & $-0.050^{* *}$ & 0.034 & $-0.384^{* * *}$ & $0.269^{* *}$ & $-0.400^{* * *}$ & $0.272^{* *}$ \\
& $(0.024)$ & $(0.024)$ & $(0.097)$ & $(0.132)$ & $(0.101)$ & $(0.131)$ \\
\hline SBUs fixed effects & Yes & Yes & No & No & No & No \\
Climatic zones fixed effects & No & No & Yes & Yes & Yes & Yes \\
Observations & 8,600 & 8,600 & 8,600 & 8,600 & 8,600 & 8,600 \\
R-squared & 0.424 & 0.341 & & & & \\
\hline Notes: Standard & & & & &
\end{tabular}

Notes: Standard errors in parenthesis. ${ }^{* * *},{ }^{*}$, and $*$ stand for significant at $1 \%, 5 \%$ and $10 \%$ level.

Source: Authors' estimation from the Madagascar Young Adult Survey and ESPAM. 